\title{
Progress Report on Alloy 617 Isochronous Stress-Strain Curves
}

\author{
J. K. Wright and R. N. Wright
}

\author{
March 2014
}

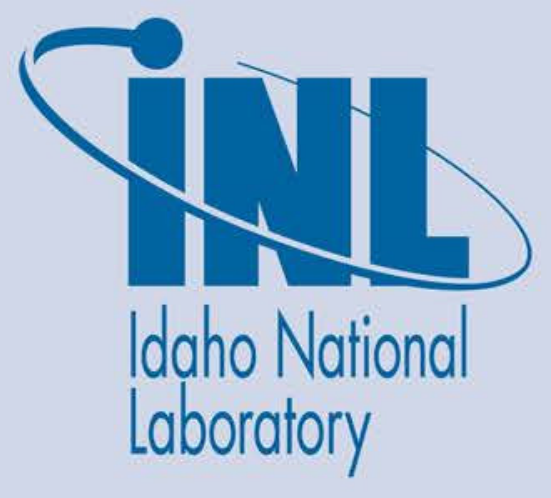

The INL is a U.S. Department of Energy National Laboratory operated by Battelle Energy Alliance 


\section{DISCLAIMER}

This information was prepared as an account of work sponsored by an agency of the U.S. Government. Neither the U.S. Government nor any agency thereof, nor any of their employees, makes any warranty, expressed or implied, or assumes any legal liability or responsibility for the accuracy, completeness, or usefulness, of any information, apparatus, product, or process disclosed, or represents that its use would not infringe privately owned rights. References herein to any specific commercial product, process, or service by trade name, trade mark, manufacturer, or otherwise, does not necessarily constitute or imply its endorsement, recommendation, or favoring by the U.S. Government or any agency thereof. The views and opinions of authors expressed herein do not necessarily state or reflect those of the U.S. Government or any agency thereof. 
INL/EXT-14-31580

\title{
Progress Report on Alloy 617 Isochronous Stress-Strain Curves
}

\author{
J. K. Wright and R. N. Wright
}

March 2014

Idaho National Laboratory Idaho Falls, Idaho 83415

\author{
http://www.inl.gov
}

Prepared for the

U.S. Department of Energy

Office of Nuclear Energy

Under DOE Idaho Operations Office

Contract DE-AC07-05ID14517 



\title{
Baseline Concept Description of a Small Modular High Temperature Reactor
}

\author{
INL/EXT-14-31541
}

May 2014

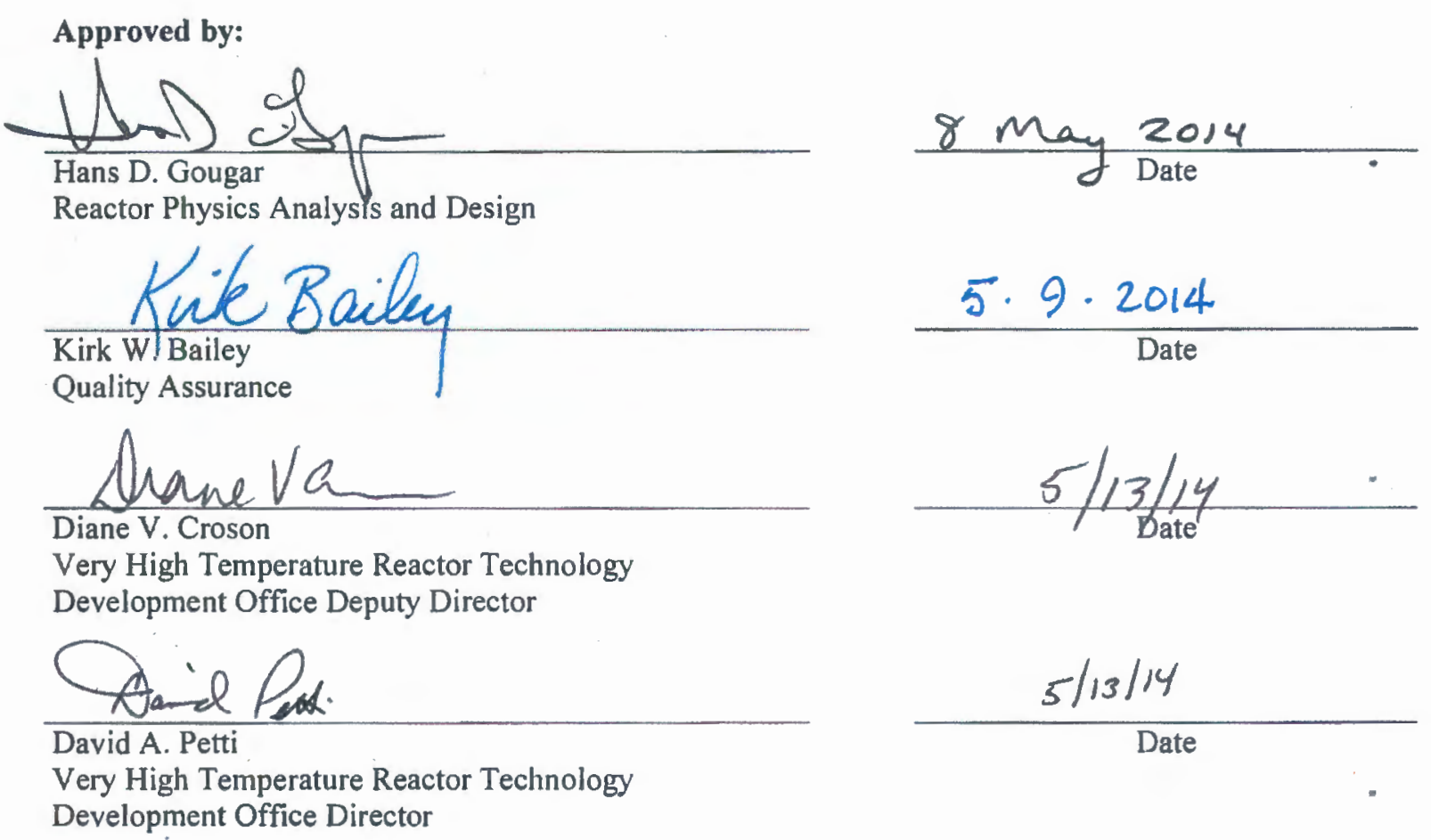




\begin{abstract}
Isochronous stress-strain curves for Alloy 617 up to a temperature of $1000^{\circ} \mathrm{C}$ will be required to qualify the material for elevated temperature design in Section III, Division 1, Subsection NH of the ASME

Boiler and Pressure Vessel Code. Several potential methods for developing these curves are reviewed in this report. It is shown that in general power-law creep is the rate controlling deformation mechanism for a wide range of alloy heats, test temperatures and stresses. Measurement of the strain rate sensitivity of Alloy 617 indicates that the material is highly strain rate sensitive in the tensile deformation range above about $750^{\circ} \mathrm{C}$. This suggests that the concept of a hot tensile curve as a bounding case on the isochronous stress-strain diagrams is problematic. The impact of strain rate on the hot tensile curves is examined and it is concluded that incorporating such a curve is only meaningful if a single tensile strain rate (typically the ASTM standard rate of $0.5 \% / \mathrm{min}$ ) is arbitrarily defined. Current experimentally determined creep data are compared to isochronous stress-strain curves proposed previously by the German programs in the 1980s and by the 1990 draft ASME Code Case. Variability in how well the experimental data are represented by the proposed design curves that suggests further analysis is necessary prior to completing a new draft Code Case.
\end{abstract}




\section{CONTENTS}

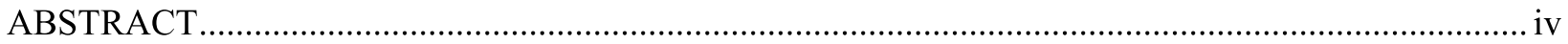

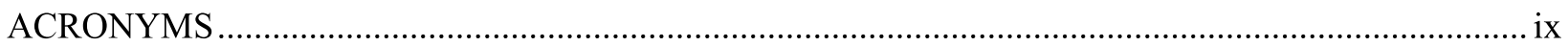

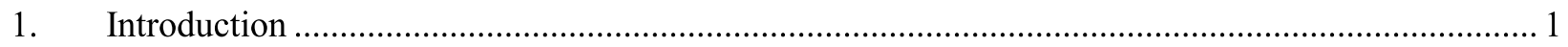

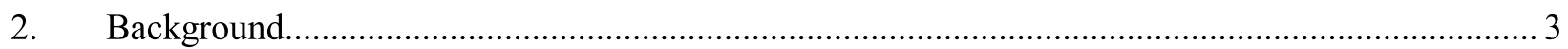

3. Existing Isochronous and Hot Tensile Stress-Strain Curves ........................................................ 5

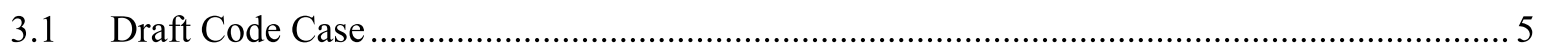

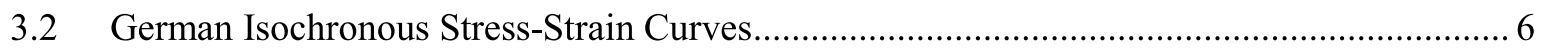

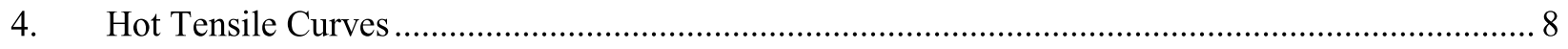

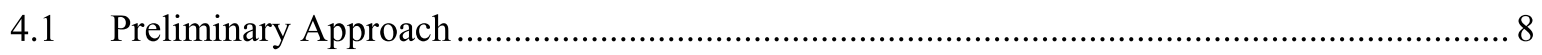

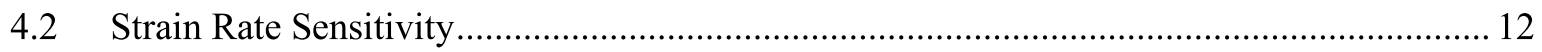

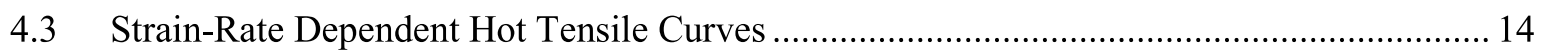

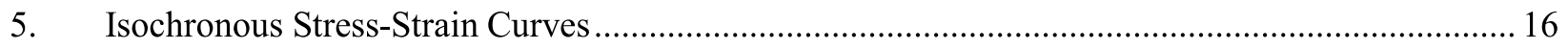

5.1 Preliminary Approach using Zener-Hollomon.......................................................... 16

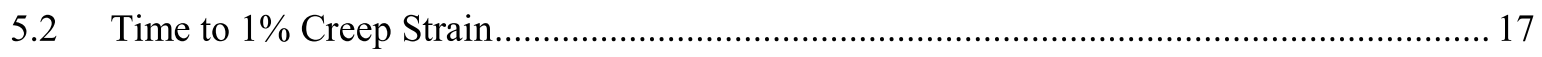

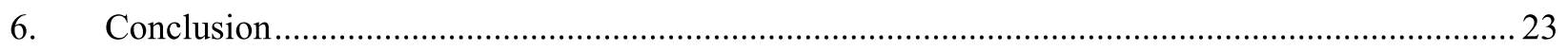

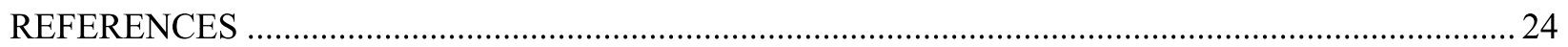

\section{FIGURES}

Figure 1. Schematic of a series of creep curves for various stresses at one temperature of interest for a VHTR material.

Figure 2. Isochronous stress-strain curves derived from the creep curves shown schematically in Figure 1.

Figure 3. Isochronous stress-strain curves for Type 304 stainless steel from Section III, Division 1 Subsection NH of the ASME Code.

Figure 4. Deformation mechanism map for Alloy 617 showing the VHTR service envelope with superimposed tensile and creep data .....

Figure 5. Larson-Miller plot for numerous heats of Alloy 617 from various well documented sources.

Figure 6. Average isochronous stress-strain curves at $927^{\circ} \mathrm{C}$, presented in the draft Code Case............... 6

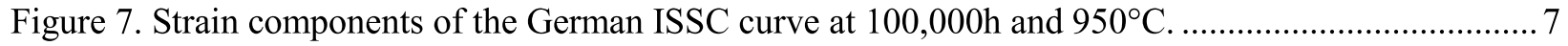

Figure 8. Comparison of German and Draft Code Case isochronous curves for 100,000 hours at $750^{\circ} \mathrm{C}$ and $760^{\circ} \mathrm{C}\left(1400^{\circ} \mathrm{F}\right)$. 
Figure 9. Yield Strength vs. Temperature for Alloy 617 compared to ASME and draft Code Case

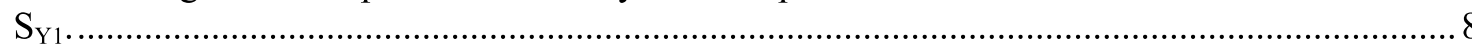

Figure 10. Comparison of experimental curves from tensile testing of bar stock (thin dashed lines) to curves calculated from a modified Voce equation (thick lines).

Figure 11. Comparison of experimental curves from tensile testing of plate stock (thin dashed lines) to curves calculated from a modified Voce equation (thick lines).

Figure 12. Comparison of Voce hot tensile curves to hot tensile curves from the draft Code Case........... 12

Figure 13. Strain rate jump data for strain controlled tests............................................................... 13

Figure 14. Stress vs. strain rate for each temperature, based on strain-controlled tests........................... 14

Figure 15. Hot tensile curves for various strain rates shown for two temperatures.................................. 15

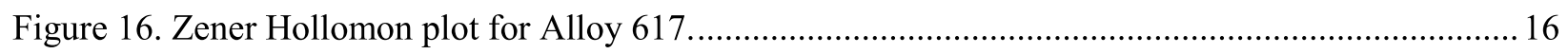

Figure 17. Time to $1 \%$ creep strain plotted with stress using the Larson-Miller parameter...................... 17

Figure 18. Comparison of $800^{\circ} \mathrm{C}$ experimental creep curves to calculated average creep curves up to $2 \%$ creep strain based on a) a Larson-Miller equation for a range of temperatures (Figure 17), and b) fits to temperature-specific curves (Figure 19) ...................................... 18

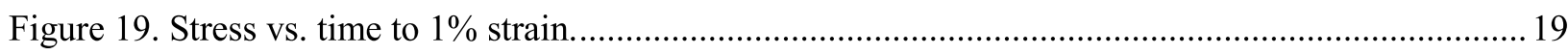

Figure 20. Isochronous stress-strain curves for $800^{\circ} \mathrm{C}$ claculated from L-M and strain to $1 \%$ creep. 19

Figure 21. Comparison of calculated ISSC to ISSC presented in the draft Code Case. ..........................20

Figure 22. Comparison of calculated ISSC to those determined in the German program.......................2 21

Figure 23. Draft Code Case isochronous stress-strain curves for $760^{\circ} \mathrm{C}$ with $750^{\circ} \mathrm{C}$ experimental data from INL and ANL (Argonne National Laboratory) on INL reference plate.

Figure 24. German isochronous stress-strain curves with experimental data from ANL on INL reference plate for $950^{\circ} \mathrm{C}$.

\section{TABLES}

Table 1. $m$ values calculated from individual jumps and curve fits of log strain rate vs. log stress for strain-controlled tests. 


\section{ACRONYMS}

ANL - Argonne National Laboratory

ASME - American Society of Mechanical Engineers

BPV - ASME Boiler and Pressure Vessel Code

HTGR - High Temperature Gas Reactor

INL - Idaho National Laboratory

ISSC - Isochronous Stress-Strain Curve

L-M - Larson-Miller

VHTR - Very High Temperature Reactor

Z-H - Zener-Hollomon 


\section{Progress Report on Alloy 617 Isochronous Stress- Strain Curves}

\section{Introduction}

The creep behavior of nickel alloys at temperatures relevant to Very High Temperature Reactor (VHTR) applications can be represented in a number of different ways. A Larson-Miller (L-M) plot, for example, allows a single representation of rupture life that incorporates the effect of stress, time, and temperature. Creep strain as a function of time can be represented as a series of creep curves for different stresses for a fixed temperature. Typical behavior for a VHTR alloys is shown schematically in Figure 1 in the form of idealized creep curves. For simplified design analysis in the creep regime it is often desirable to represent the material behavior as a series of isochronous stress-strain curves (ISSC). The creep curves shown schematically in Figure 1are represented as ISSC in Figure 2. These curves represent the stress-strain behavior for a particular time of interest.

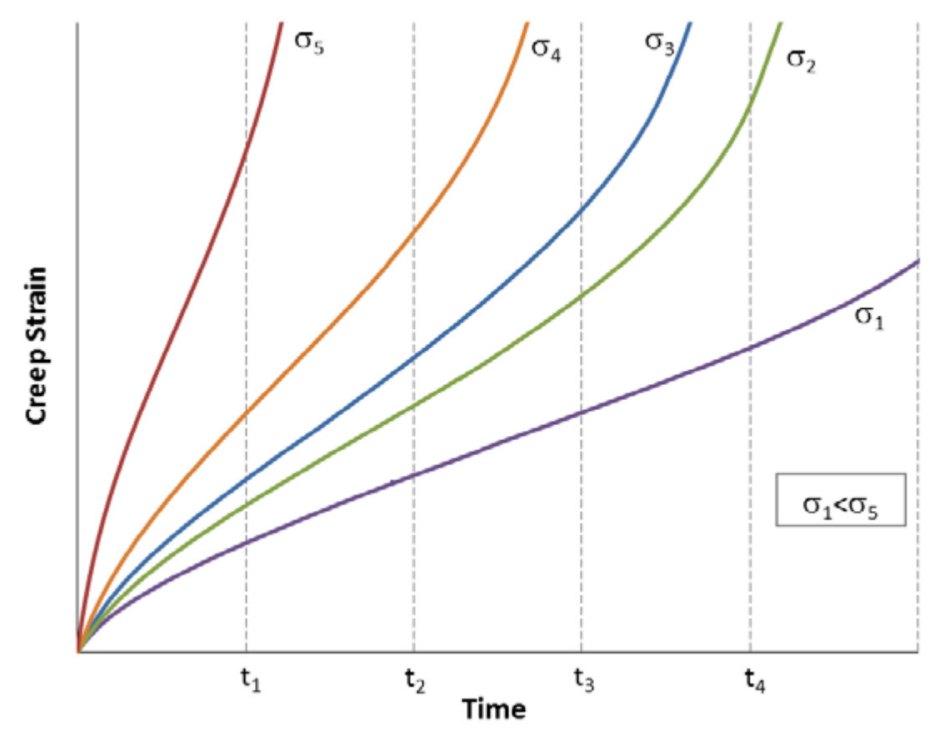

Figure 1. Schematic of a series of creep curves for various stresses at one temperature of interest for a VHTR material. 


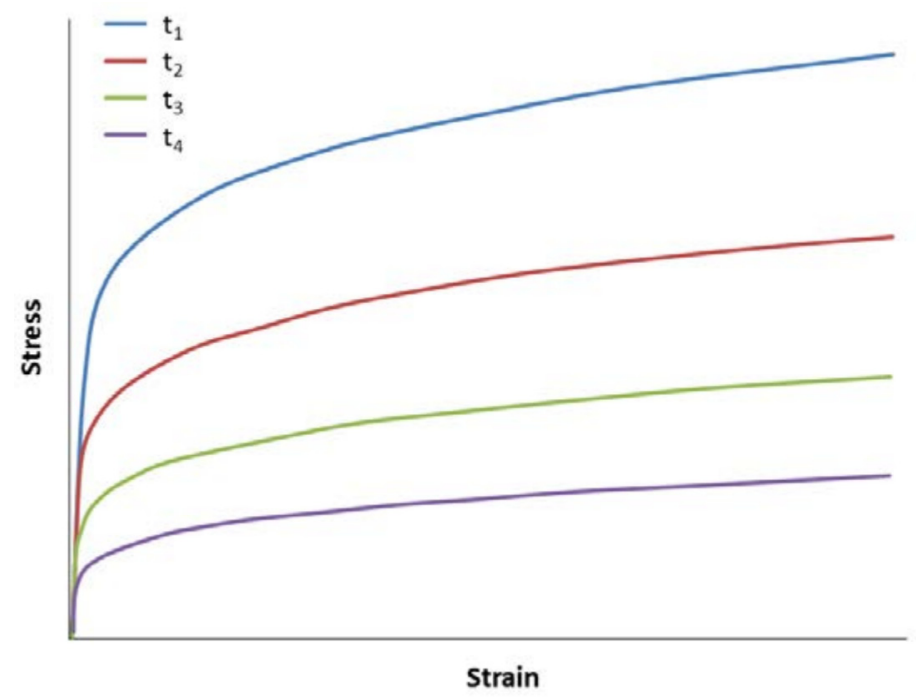

Figure 2. Isochronous stress-strain curves derived from the creep curves shown schematically in Figure 1.

In a survey of the utility of isochronous stress-strain curves in design, Marriott notes that this approach is frequently quite useful for applications in simplified design methods. ${ }^{1}$ It is also noted that the isochronous curve approach is not strictly correct; in theoretical mechanics it is the creep rate and not the total creep strain that is the significant variable in determining time dependent behavior. ${ }^{2,3}$ In part this is true because there is frequently found to be history dependence in creep deformation and the isochronous curves are determined for constant stress (or more typically constant load) uniaxial tests.

The most prominent use of isochronous curves in engineering design is for use in Section III Division 1, Subsection NH in the ASME Boiler and Pressure Vessel Code. An example of the ISSC for Type 304 stainless steel from the Code is shown in Figure 3. In this figure, curves are shown for a temperature of $621{ }^{\circ} \mathrm{C}$ for times from one hour to 300,000 hours and a creep strain up to $2.2 \%$. Note that in addition to the time dependent behavior, Subsection $\mathrm{NH}$ requires a hot tensile curve representative of the appropriate temperature as shown for Type 304 stainless steel in Figure 3. Curves must be provided for the range of temperatures over which the alloy is to be qualified for elevated temperature design for temperatures in $50^{\circ} \mathrm{C}$ increments. 


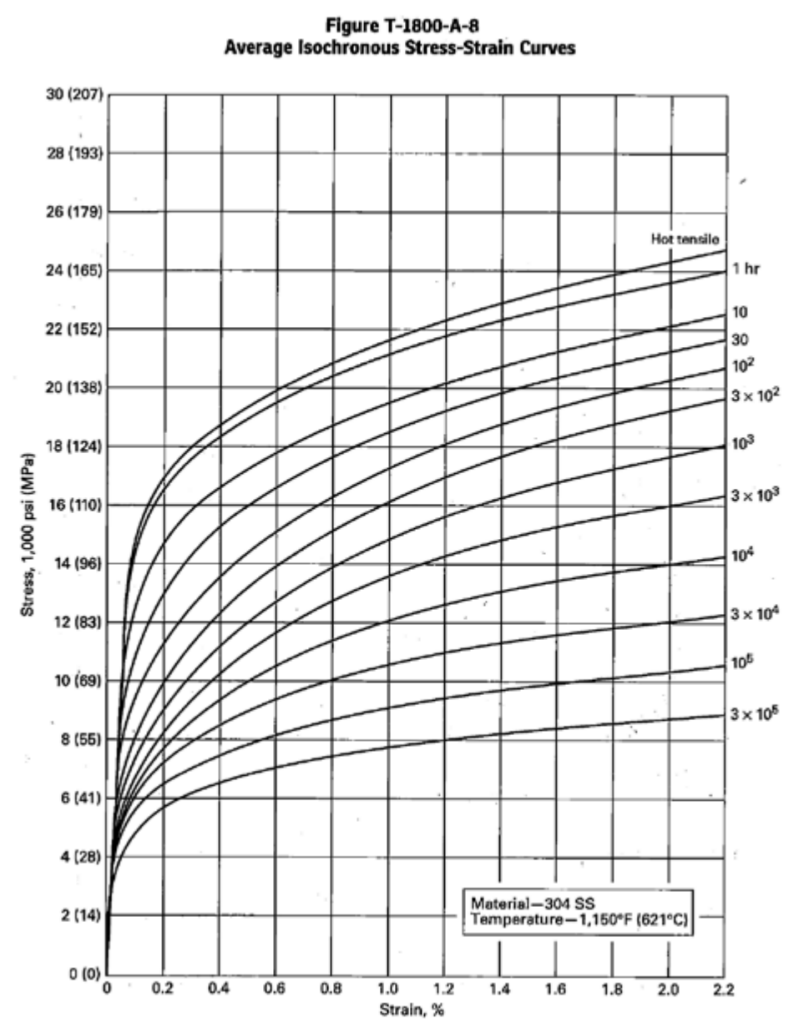

Figure 3. Isochronous stress-strain curves for Type 304 stainless steel from Section III, Division 1 Subsection NH of the ASME Code.

Isochronous curves have been developed previously for Alloy 617 for some temperatures of interest to VHTR heat exchanger design by the German development programs in the 1980s and for the draft ASME Code Case submitted in 1990. This report summarizes progress on the current effort to determine ISSC to support Code qualification of Alloy 617 based on historical and contemporary measurement of the creep properties of this alloy. The range of temperatures of interest for the current effort is 427 to $1000^{\circ} \mathrm{C}$ and the maximum design time is limited to 100,000 hours.

\section{Background}

In the 1970s and 1980s Alloy 617 was under investigation in the US as well as in Germany and Japan as a candidate material for use in high temperature gas-cooled reactors (HTGRs). During that time, significant data were generated on the elevated tensile and creep properties of the alloy. However, the maximum duration of creep tests reported was $20,000-40,000 \mathrm{~h}$, an order of magnitude less than the expected service life for future HTGRs of 60 years $(526,000 \mathrm{~h})$. Creep curves generated outside the US has thus far not been available, with the exception of a small amount presented in the open literature, and only rupture time and other summary information (not the creep curves) are available for much of the testing performed in the US. ${ }^{4}$

A variety of constitutive models for creep deformation of Alloy 617 have been evaluated, ranging from simple power-law creep, to modified power-law equations incorporating internal stress components and activation energy, to complex unified constitutive models that can sometimes provide an excellent fit to available creep data. ${ }^{5,6}$ In most cases, a simple power-law model provides a reasonable fit, however, predicting behavior at longer times by extrapolating the power law to stresses below the current database could result in non-conservative predictions of creep strain. 4 
Fine grained microstructures may exhibit higher creep rates, for example by Coble creep (grain boundary diffusion), with creep underpredicted by the current database. ${ }^{4}$ Fine grained material could potentially exhibit alternative deformation modes such as grain boundary sliding, in addition to creep. Typically Alloy 617 is put into service in a mill annealed condition with coarse grains $(>100 \mu \mathrm{m}$ is common), however, it is possible that fine grain material may result from recrystallization associated with sheet rolling for compact heat exchangers or through recrystallization in service of mill annealed material that is cold worked during fabrication.

One means of assessing rate controlling creep mechanisms as a function of temperature and stress is the deformation mechanism map. A deformation mechanism map proposed by the German research program in the 1980s for Alloy 617 with conventional grain size is shown in Figure 4. Superimposed on the map are experimental data from the current VHTR program. It can be seen that the experimental data from tensile testing (plastic flow or "Sliding of Dislocations" in the figure) are appropriately described. In addition, lower strain rate data from strain rate jump tests and conventional creep tests fall in the "powerlaw creep" region. Independent measurement of the creep exponent has shown that power-law creep is the rate controlling mechanism for these tests. Note that there is a triangular region of stress and temperature that represents the anticipated design space for a VHTR heat exchanger and it is well within the powerlaw creep region.

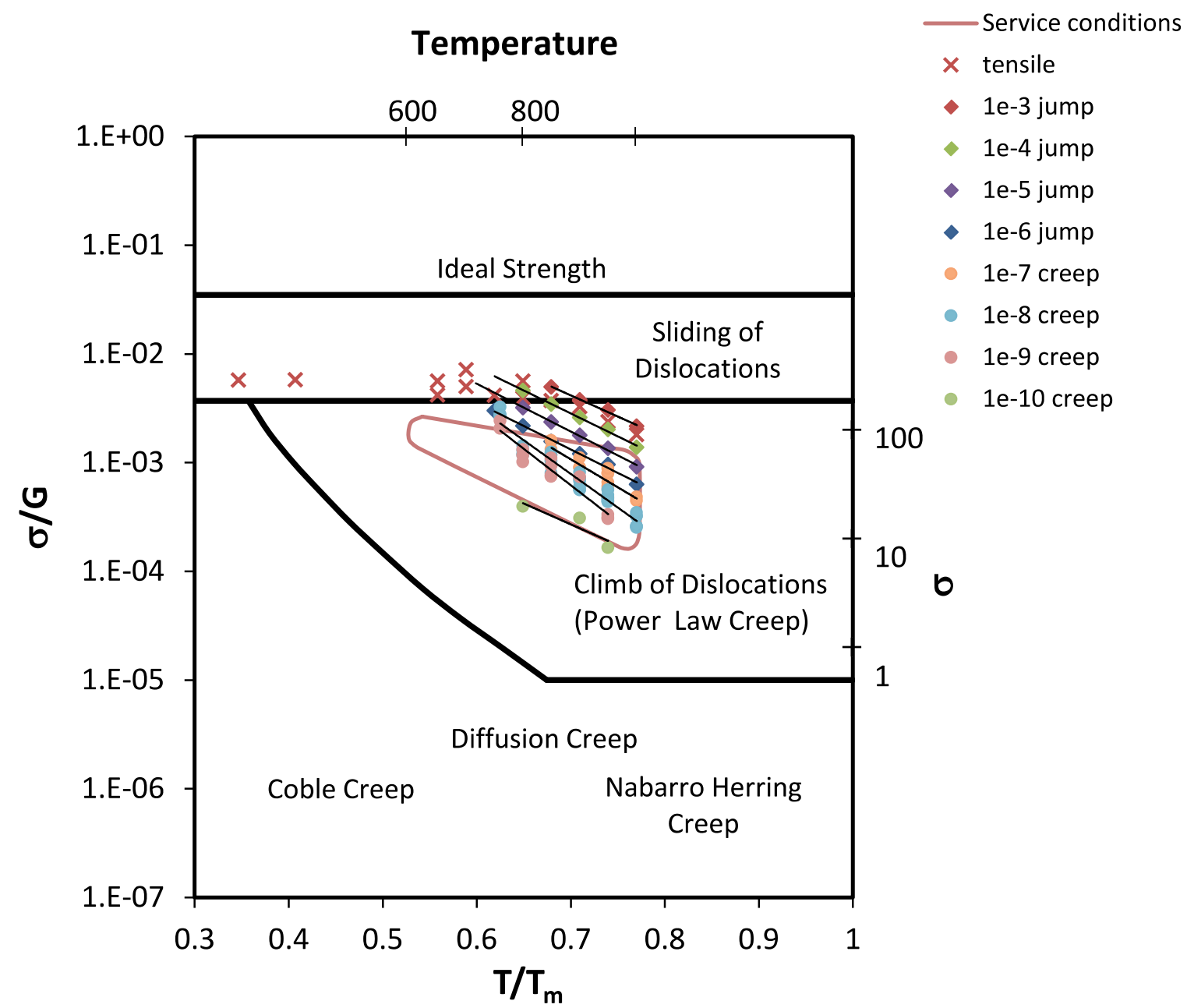

Figure 4. Deformation mechanism map for Alloy 617 showing the VHTR service envelope with superimposed tensile and creep data . 
Another way of characterizing a large amount of creep rupture data from both the historical record and contemporary experiments is to use the Larson-Miller approach to normalizing for stress, temperature and time. A plot for all of the well documented data from the literature and several contemporary research programs is shown in Figure 5. A single line fits these data even for low stress (high L-M numbers) and gives further confidence that for a very wide range of test conditions, heats of material and product forms a single mechanism is rate controlling. Based on this combined evidence it appears that a single set of isochronous stress-strain curves will represent behavior of Alloy 617 for design purposes as long as the microstructure is properly accounted for.

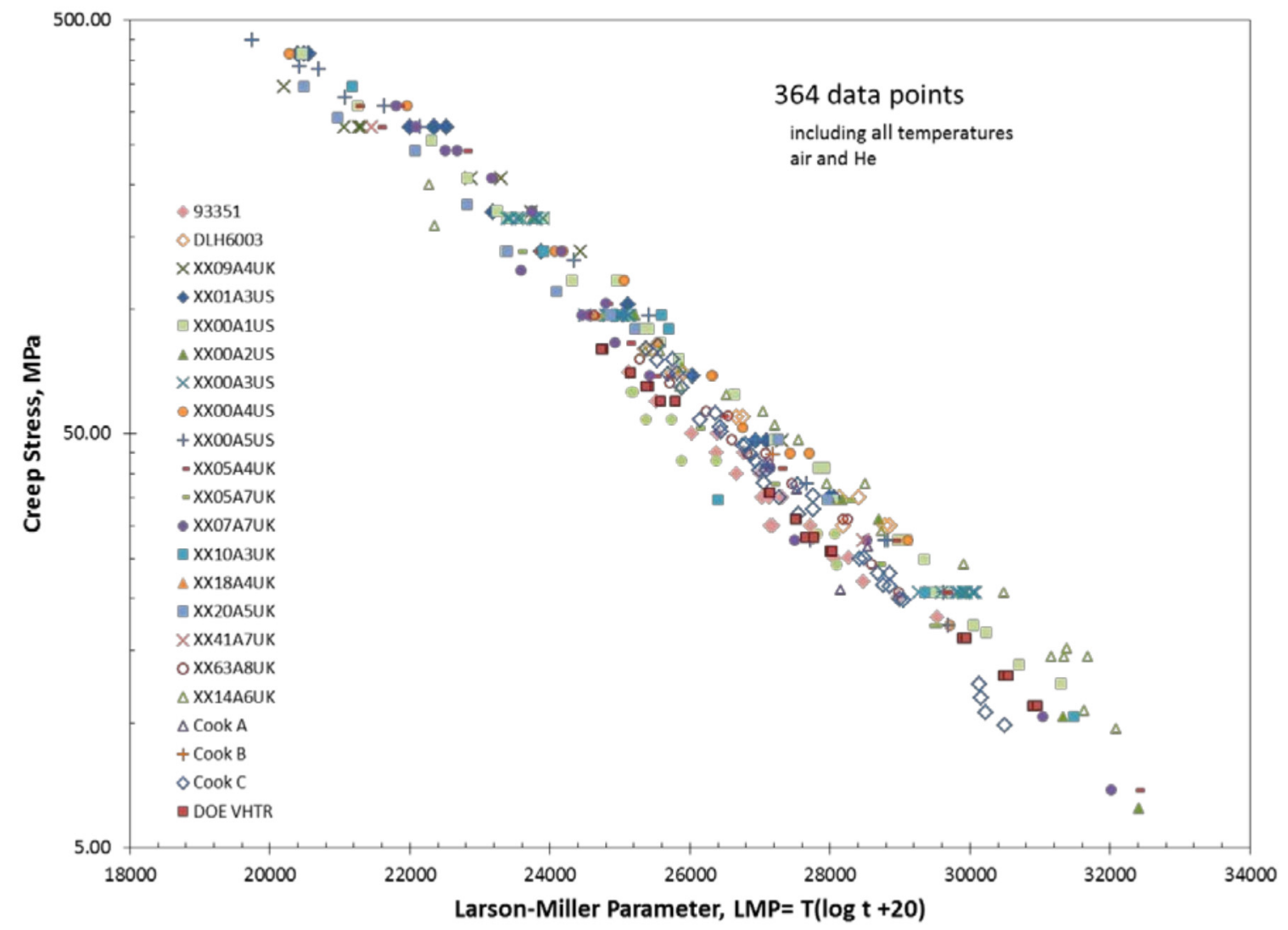

Figure 5. Larson-Miller plot for numerous heats of Alloy 617 from various well documented sources.

\section{Existing Isochronous and Hot Tensile Stress-Strain Curves 3.1 Draft Code Case}

Isochronous stress-strain curves and hot tensile curves for temperatures of $1200-1800^{\circ} \mathrm{F}$ at $1000^{\circ} \mathrm{F}$ intervals $\left(649,704,760,816,871,927\right.$ and $982^{\circ} \mathrm{C}$ ) are contained in the Alloy 617 draft Code Case ${ }^{7}$ (T1800 in Appendix T). They were generated from a unified constitutive model based on the results of tensile and creep tests conducted on a single typical heat of Alloy 617. Although typical constitutive models consider inelastic behavior as the sum of independently evaluated plastic (time-independent) and creep (time-dependent) strains, this method was not thought to be adequate for Alloy 617, because all inelastic behavior is time-dependent. This is exemplified by the significant strain rate sensitivity of the 
alloy at elevated temperatures. The unified constitutive model used in the draft Code Case, and outlined in Blass, Corum and Chang ${ }^{8}$, accounts for competing mechanisms of hardening and recovery and uses a set of coupled partial differential equations to analyze a data set provided by General Electric for DOE in the late 1980s. It contains a softening function that can account for yield drops observed in tensile testing, and accelerating strain observed in creep tests of Alloy 617. Trial and error was used to obtain the required parameters for each temperature in order to obtain a reasonable match to the GE tensile and creep data. Curves were further adjusted to represent average $0.2 \%$ offset yield behavior and $1 \%$ creep strain behavior reported by Huntington Alloys (now Special Metals). An example of a family of ISSC and hot tensile curves that was presented in the draft Code Case is reproduced in Figure 6 for $927^{\circ} \mathrm{C}\left(1700^{\circ} \mathrm{F}\right) .8$

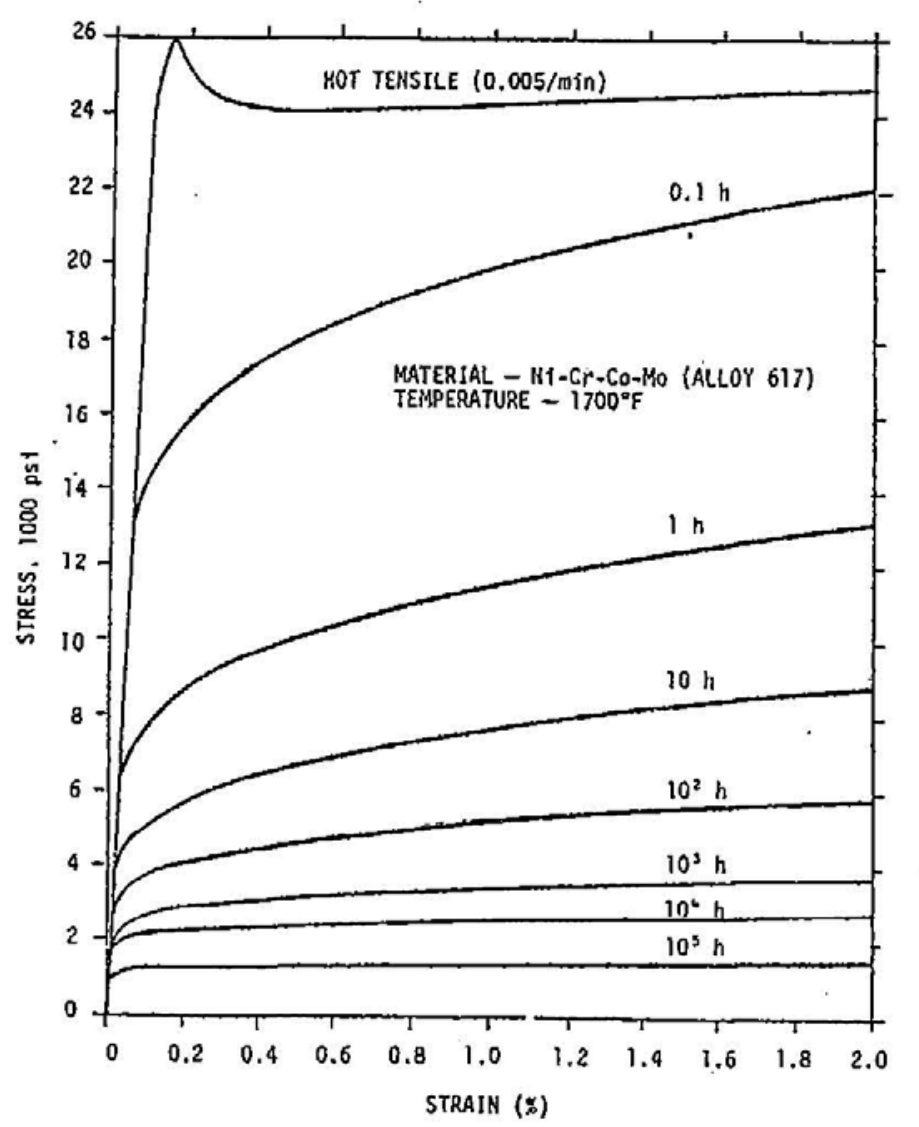

Figure 6. Average isochronous stress-strain curves at $927^{\circ} \mathrm{C}$, presented in the draft Code Case. 8

\subsection{German Isochronous Stress-Strain Curves}

ISSC were also developed as part of the German HTGR effort for times up to 100,000h and temperatures up to $950^{\circ} \mathrm{C}$. They used a more traditional approach of considering total strain to be the sum of elastic, power-law creep strain (which describes secondary, steady-state creep) and inelastic strain. The inelastic strain includes plastic strain and primary and tertiary creep strain, both of which are more rapid than secondary creep which occurs, by definition, at the minimum creep strain rate. Power-law creep accounted for only $10 \%$ of the German reported ISSC, as illustrated in Figure 7.4 It is not known if the additional inelastic strain was determined theoretically or empirically. 


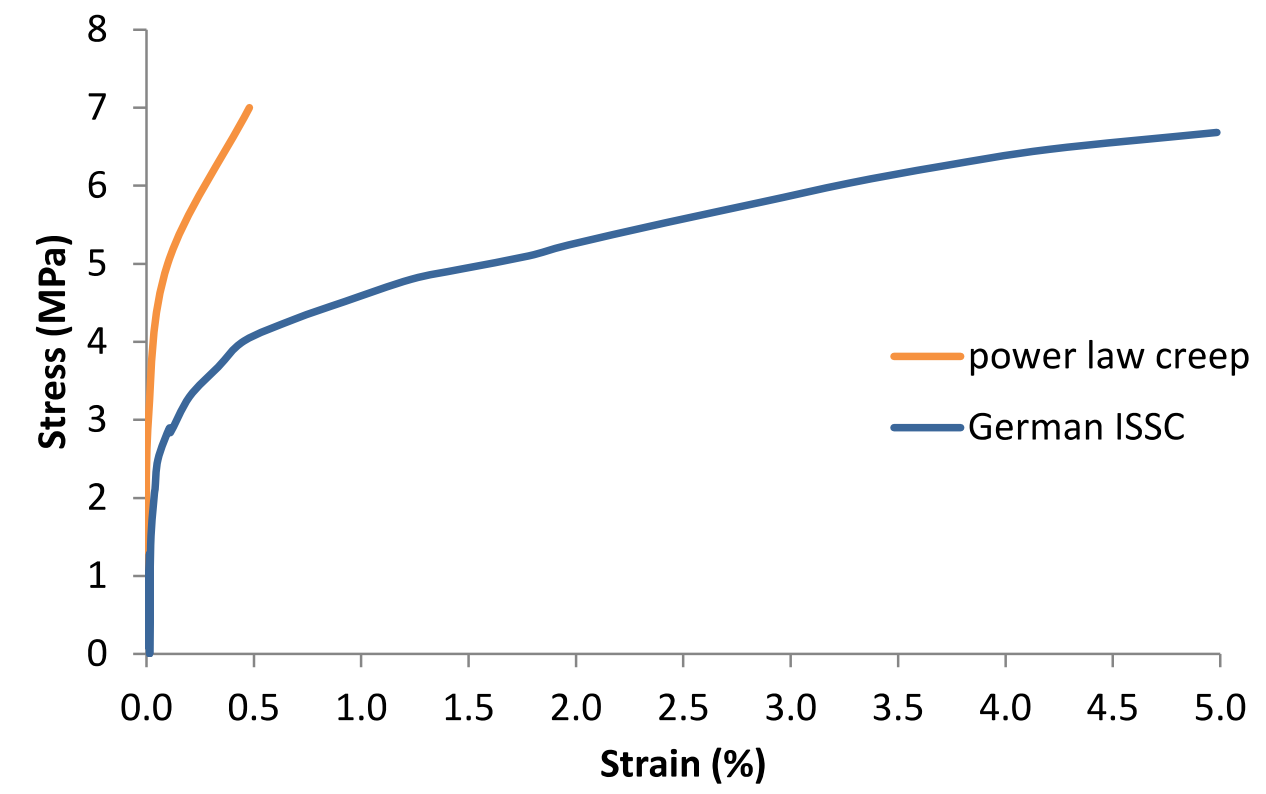

Figure 7. Strain components of the German ISSC curve at $100,000 \mathrm{~h}$ and $950^{\circ} \mathrm{C}$.

Figure 8 compares the German and Draft Code Case isochronous curves for 100,000 hours at $750^{\circ} \mathrm{C}$ and $760^{\circ} \mathrm{C}\left(1400^{\circ} \mathrm{F}\right)$. The ISSC established by the two research efforts are not very similar. The US curve generated for the ASME draft Code Case is significantly higher than the German curve, although the temperature is slightly higher. Comparisons at other temperatures are not possible because of the use of Celsius and Fahrenheit temperatures by the two groups.

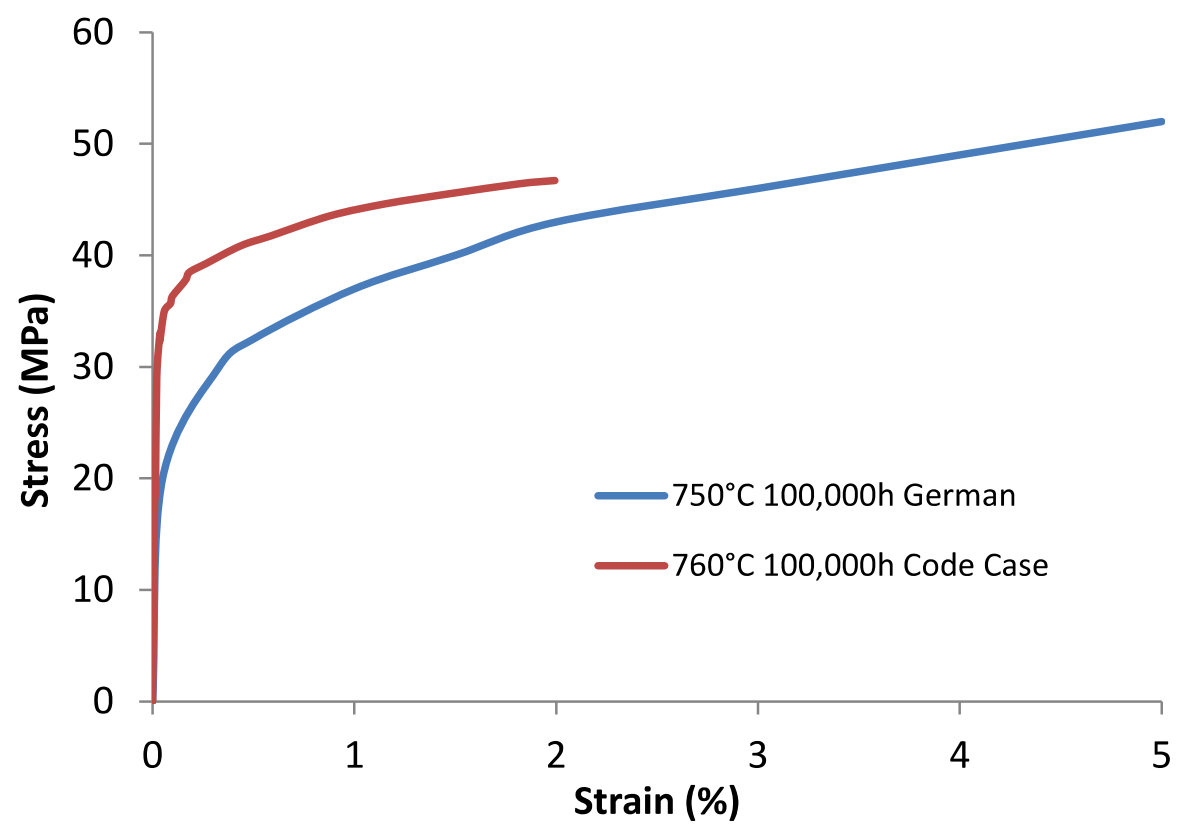

Figure 8. Comparison of German and Draft Code Case isochronous curves for 100,000 hours at $750^{\circ} \mathrm{C}$ and $760^{\circ} \mathrm{C}\left(1400^{\circ} \mathrm{F}\right)$. 


\section{Hot Tensile Curves \\ 4.1 Preliminary Approach}

A simpler approach was used as a starting point for generating hot tensile curves to model more recent data generated at Idaho National Laboratory (INL). This method is outlined by Swindeman for $9 \mathrm{Cr}-1 \mathrm{Mo}-\mathrm{V}$ steel ${ }^{9}$. First, the yield strength vs. temperature is compared to the $S_{\mathrm{Y} 1}$ trend curve from ASME Section IID, Table Y1, with high temperature values taken from the draft Code Case (for Grade 91, high temperature values were taken from ASME NH). The experimental yield strengths from both plate and bar stock fall above this line and also fall above a line corresponding to $1.25 \mathrm{~S}_{\mathrm{Y} 1}$, as shown in Figure 9.

A modified Voce equation was used to describe the tensile plasticity:

$\mathrm{S}-\mathrm{S}_{\mathrm{UTS}}=\left(\mathrm{S}_{\mathrm{pl}}-\mathrm{S}_{\mathrm{UTS}}\right) \exp \left[-\left(\mathrm{b} \mathrm{e}_{\mathrm{p}}\right)^{0.5}\right]$

where $\mathrm{S}$ is the engineering stress, $\mathrm{e}_{\mathrm{p}}$ is the engineering plastic strain, $\mathrm{S}_{\mathrm{UTS}}$ is the ultimate tensile strength, $\mathrm{S}_{\mathrm{pl}}$ is the proportional limit, and $\mathrm{b}$ is the rate constant. The latter constant can be calculated when $\mathrm{S}=\mathrm{S}_{\mathrm{y}}$, yield strength, and $e_{p}$ is $0.2 \%$. To generate a stress-strain curve, equation [1] is solved for $e_{p}$ and total strain is calculated as:

$\mathrm{e}=100 * \mathrm{~S} / \mathrm{E}+\mathrm{e}_{\mathrm{p}}$

Modulus values are taken from the ASME Code, not from the experiments. To calculate a hot tensile curve, $\mathrm{S}_{\mathrm{pl}}$ and $\mathrm{S}_{\mathrm{UTS}}$ are multiplied by the ratio, $\mathrm{R}$ :

$\mathrm{R}=1.25 \mathrm{SY} 1 / \mathrm{Sy}$

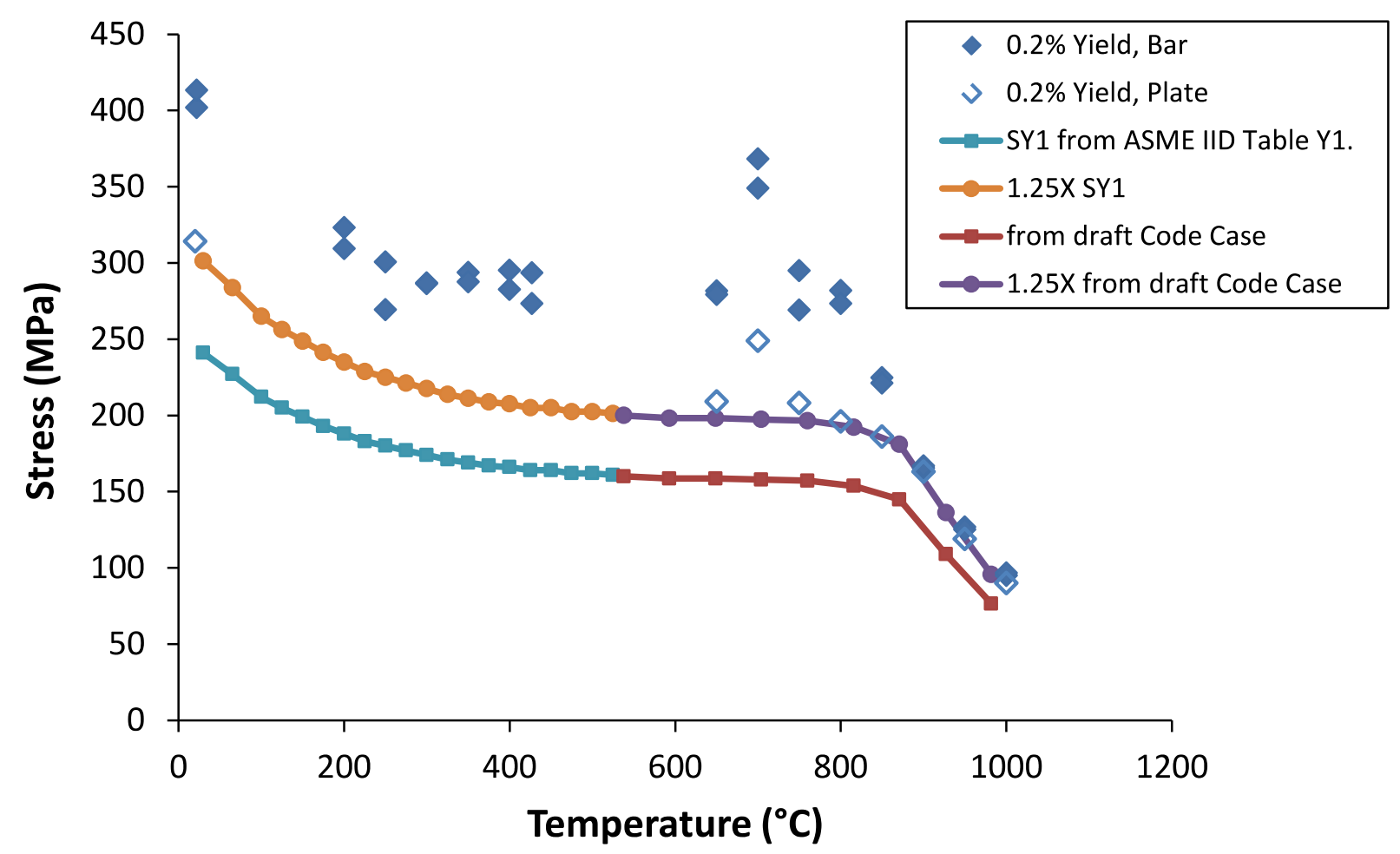

Figure 9. Yield Strength vs. Temperature for Alloy 617 compared to ASME and draft Code Case $\mathrm{S}_{\mathrm{Y} 1}$. 
As a check for proper application of this method, plots and values presented in Swindeman's work were reproduced, however, in some cases, discrepancies were found. Tabulated values in the paper do not all match $S_{\mathrm{Y} 1}$ values obtained directly from the Code, and calculations of $b$ do not match those reported in many cases. However the figure comparing experimental and Voce calculated stress-strain curve at $649^{\circ} \mathrm{C}$ can be reproduced exactly.

A comparison of calculated and experimental data for Alloy 617 bar stock is shown in Figure 10. This modified Voce equation gives good agreement with experimental data at the higher temperatures, but poor agreement at lower temperatures, especially at 427 and $700^{\circ} \mathrm{C}$. Similar results are found for tensile results on plate (Figure 11). Experimental curves exhibit significant serrated flow in the temperature range of $600-850^{\circ} \mathrm{C}$, typically associated with solute pinning.

Hot tensile curves are generated by applying the $\mathrm{R}$ ratio as described above. Design curves based on bar and plate are virtually identical for temperatures of $850^{\circ} \mathrm{C}$ and above. At lower temperatures they differ somewhat, as can be seen in Figure 12.

Hot tensile curves are plotted in Figure 12 for 650 and $750^{\circ} \mathrm{C}$ with the 649 and $760^{\circ} \mathrm{C}$ curves from the draft Code Case. The Voce curves are below the Code Case curves at all strains. Limited comparisons of this type are possible since Code Case curves were generated at $1000^{\circ} \mathrm{F}$ intervals and recent tensile results are for $50^{\circ} \mathrm{C}$ intervals. Unfortunately the temperatures available for comparison are the lower temperatures that are not well modeled by the Voce equation. Note that while the Code Case curve for $649^{\circ} \mathrm{C}$ is steeper than the Voce curves, the Voce curves are steeper than the $650^{\circ} \mathrm{C}$ data. 

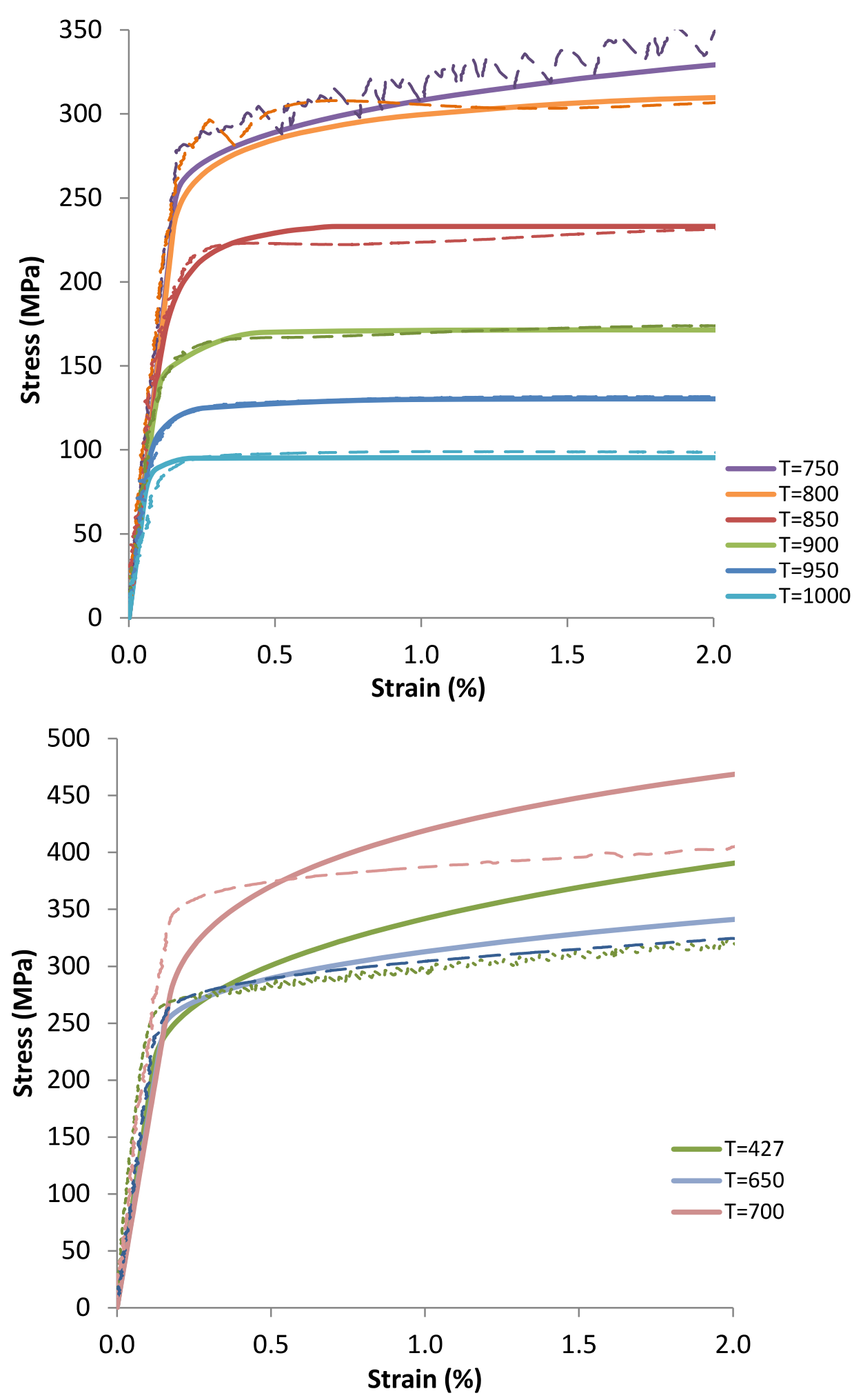

Figure 10. Comparison of experimental curves from tensile testing of bar stock (thin dashed lines) to curves calculated from a modified Voce equation (thick lines). 

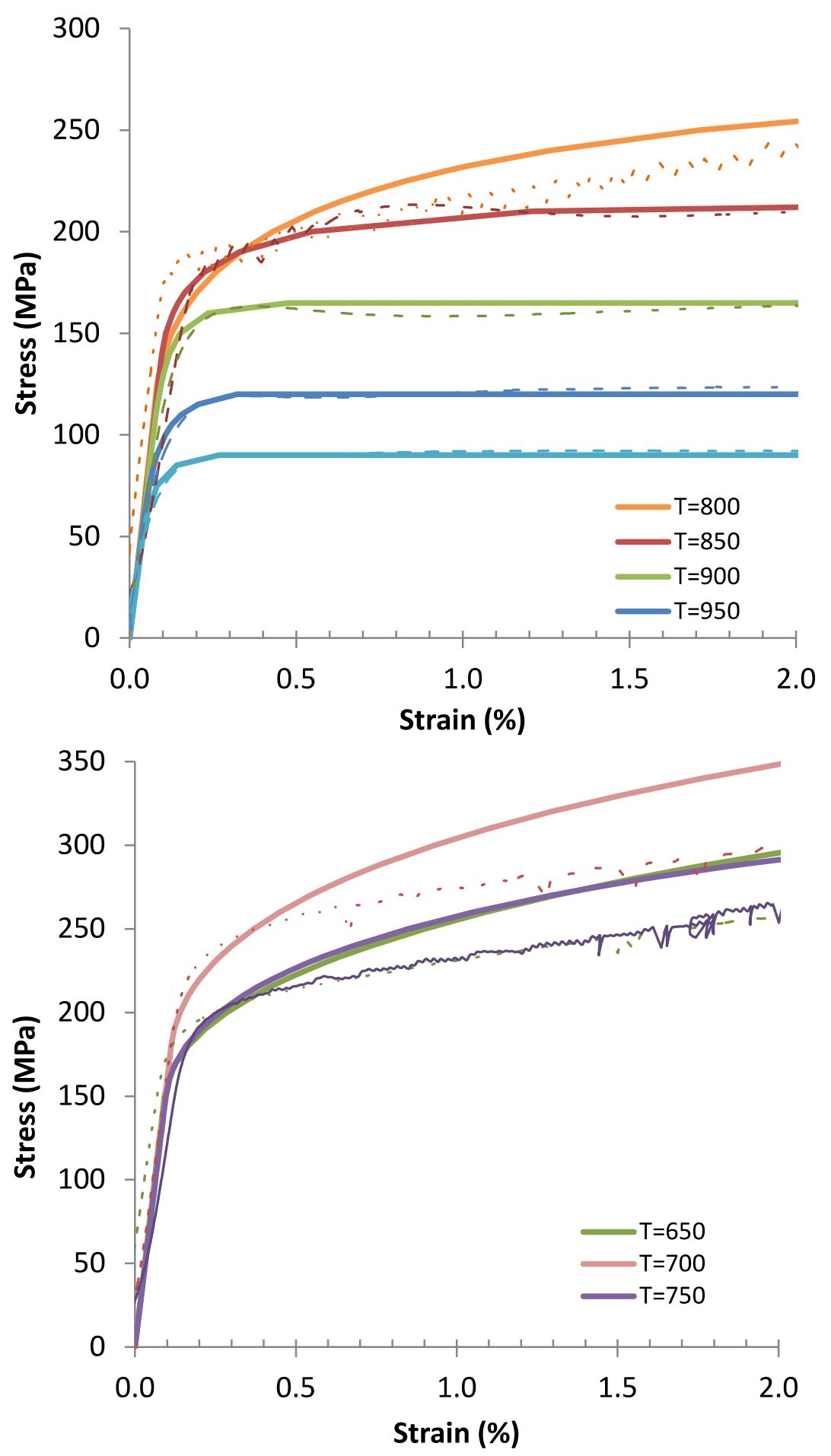

Figure 11. Comparison of experimental curves from tensile testing of plate stock (thin dashed lines) to curves calculated from a modified Voce equation (thick lines). 

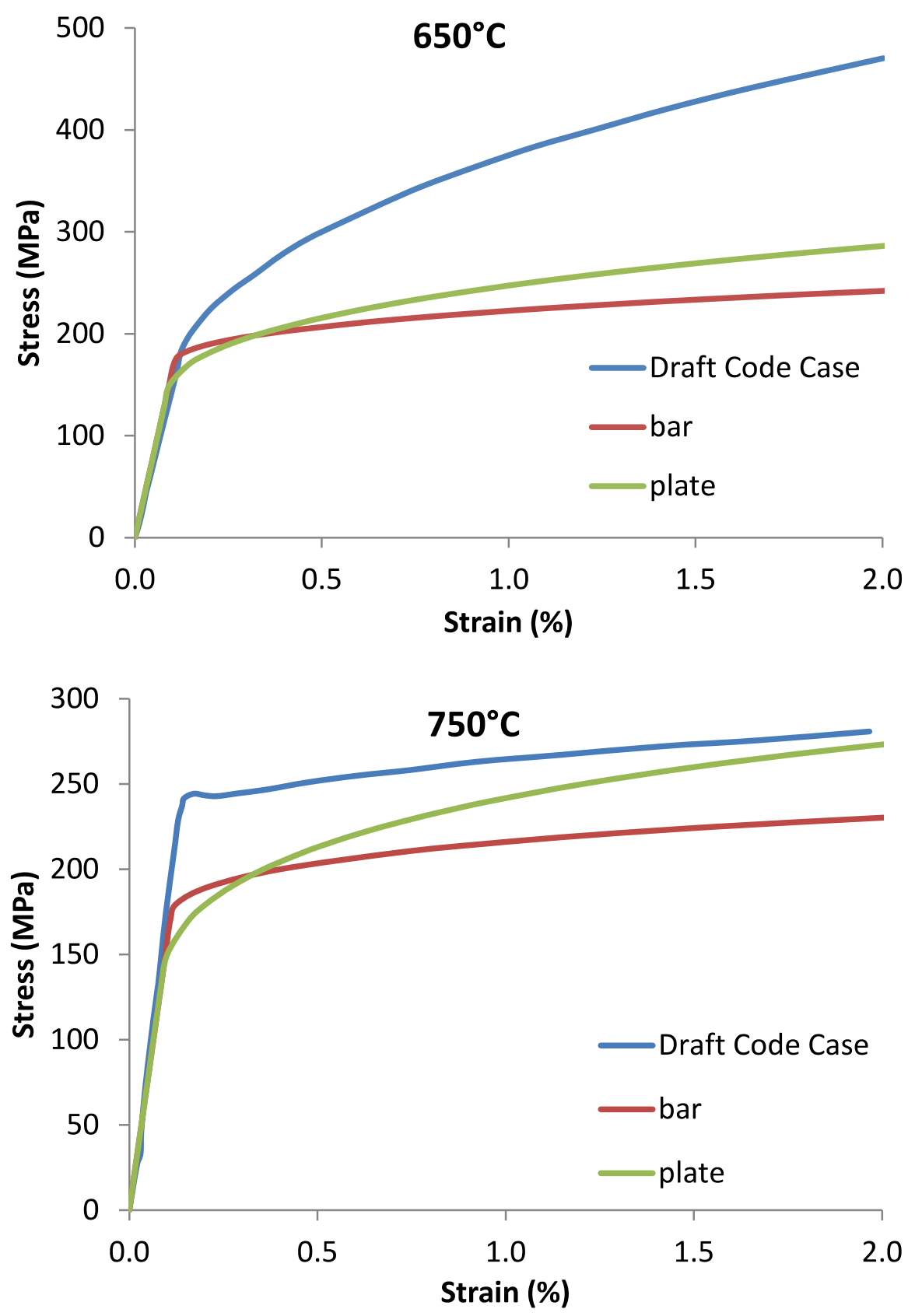

Figure 12. Comparison of Voce hot tensile curves to hot tensile curves from the draft Code Case.

\subsection{Strain Rate Sensitivity}

For engineering design it is typically assumed that there is a unique flow stress for a material, independent of strain rate, below which there is negligible inelastic deformation. In the temperature range of $800-1000^{\circ} \mathrm{C}$ the flow behavior of Alloy 617 is highly dependent on strain rate. ${ }^{10,11,12}$ For example at $900^{\circ} \mathrm{C}$ the flow stress of Alloy 617 increases from $50 \mathrm{MPa}$ at $10^{-6} / \mathrm{s}$ to $250 \mathrm{MPa}$ at $10^{-2} / \mathrm{s}^{13}$ A typical strain rate for a tensile tests used to determine the flow stress is $10^{-3} / \mathrm{s}$. Thus, strain rate will affect the allowable stress values used in engineering design in the temperature range of interest for hot gas piping and intermediate heat exchanger components. 
To characterize strain rate sensitivity, it is common to carry out strain rate jump tests, where a single specimen is tested at a given strain rate until a steady state flow stress is obtained and then the strain rate is rapidly increased to obtain the flow stress at the next incremental strain rate. Results of strain rate jump tests run in strain control for Alloy 617 are shown in Figure 13. The transient flow stress behavior observed immediately after the change in strain rate presents difficulty in determining what stress to use for strain rate sensitivity determination. Figure 13 also illustrates how the stress was selected, based on Mulford and Kocks. ${ }^{14}$

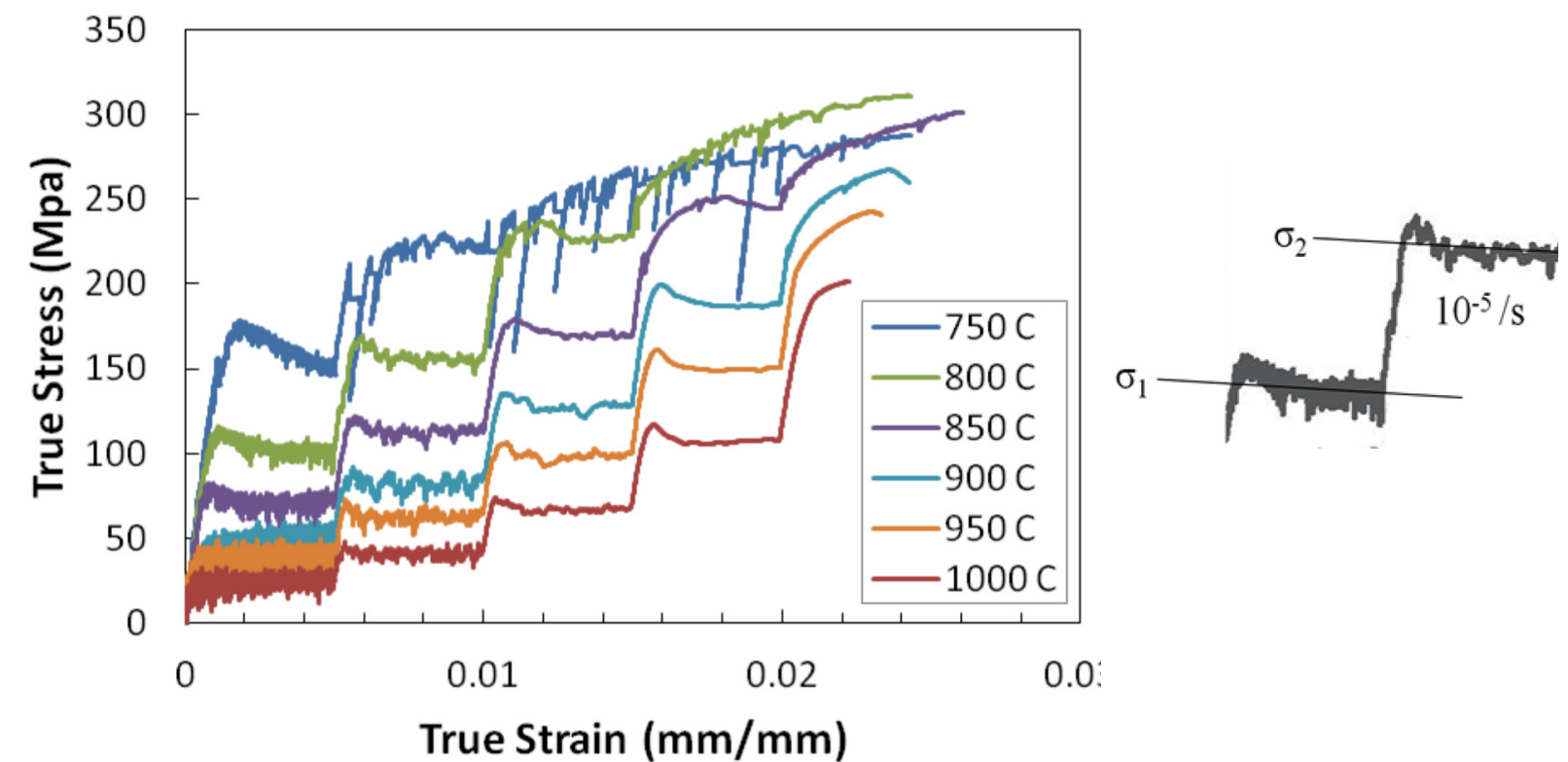

Figure 13. Strain rate jump data for strain controlled tests.

Jump testing indicates the flow stress and strain rate are typically related at a constant temperature and strain by a power-law hardening equation:

$\sigma=\mathrm{C}(\varepsilon)^{\mathrm{m}}$

where $\mathrm{C}$ is a constant, $\varepsilon$ is the strain rate and $\mathrm{m}$ is the strain rate sensitivity. The strain rate sensitivity is therefore the slope of a log-log plot of the true stress and strain rate shown in Figure 14 . The $750^{\circ} \mathrm{C}$ test is not included because of the difficulty discerning the jumps. The numerical value of the strain rate sensitivity exponent, $m$, can be determined for each jump from the instantaneous change in stress associated with an instantaneous change in strain rate, where subscripts 1 and 2 indicate values before and after the jump:

$m=\frac{\log \left(\frac{\sigma_{2}}{\sigma_{1}}\right)}{\log \left(\frac{\dot{\varepsilon}_{2}}{\dot{\varepsilon}_{1}}\right)} \mathrm{m}=\frac{\log \left(\frac{\sigma_{2}}{\sigma_{1}}\right)}{\log \left(\frac{\text { strainrate }_{2}}{\text { strainrate }_{1}}\right)}$

Table 1 gives the $\mathrm{m}$ values calculated for each jump as well as value obtained from the slopes in Figure 14 (labeled as "fit"). 


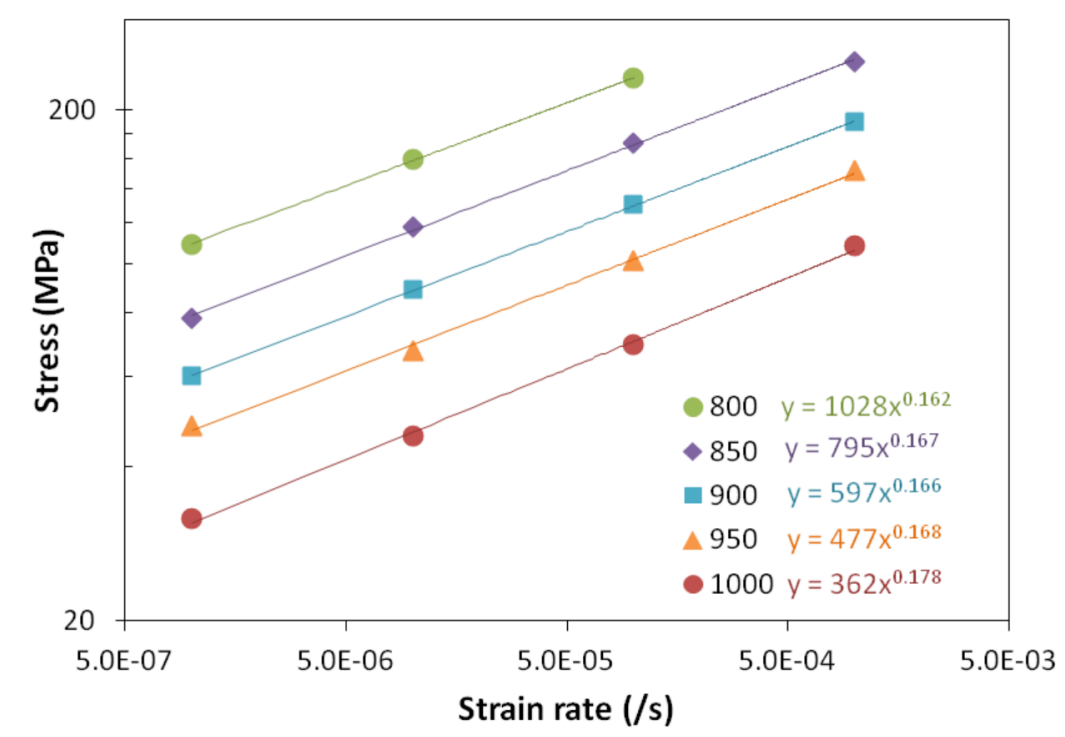

Figure 14. Stress vs. strain rate for each temperature, based on strain-controlled tests.

Table 1. $\mathrm{m}$ values calculated from individual jumps and curve fits of log strain rate vs. log stress for strain-controlled tests.

\begin{tabular}{|l|l|l|l|l|l|l|}
\hline \multicolumn{2}{|c|}{ Strain Rate (/sec) } & \multicolumn{5}{c|}{ Temperature $\left({ }^{\circ} \mathbf{C}\right)$} \\
\hline Mid & Jump & $\mathbf{8 0 0}$ & $\mathbf{8 5 0}$ & $\mathbf{9 0 0}$ & $\mathbf{9 5 0}$ & $\mathbf{1 0 0 0}$ \\
\hline $5 \times 10^{-6}$ & $10^{-6}$ to $10^{-5}$ & 0.17 & 0.18 & 0.17 & 0.15 & 0.16 \\
\hline $5 \times 10^{-5}$ & $10^{-5}$ to $10^{-4}$ & 0.16 & 0.16 & 0.16 & 0.18 & 0.18 \\
\hline $5 \times 10^{-4}$ & $10^{-4}$ to $10^{-3}$ & -- & 0.16 & 0.16 & 0.18 & 0.19 \\
\hline & fit & 0.16 & 0.17 & 0.17 & 0.17 & 0.18 \\
\hline
\end{tabular}

\subsection{Strain-Rate Dependent Hot Tensile Curves}

It is possible to examine the influence of strain rate on hot tensile curves based on the results of strain rate sensitivity testing. Tensile testing on the Alloy 617 bar and plate stock was performed at about $0.6 \% / \mathrm{min}$. Throughout this temperature range, $\mathrm{m}$ is approximately 0.17 , as indicated in Table 1 . Using these $\mathrm{m}$ and $\dot{\varepsilon}$ values, the constant, $\mathrm{C}$, was calculated as a function of stress. Stress was then recalculated for strain rates of 0.06 and $6 \% / \mathrm{min}$. Results are shown in Figure 15 for two temperatures. All inelastic strain is time dependent (there is not time-independent plasticity) above temperatures of about $750^{\circ} \mathrm{C}$ for alloy 617. Therefore, a tensile test at a slower strain rate appears similar to an ISSC derived from creep tests, falling below the hot-tensile curve, although strain rate rather than stress is held constant. 

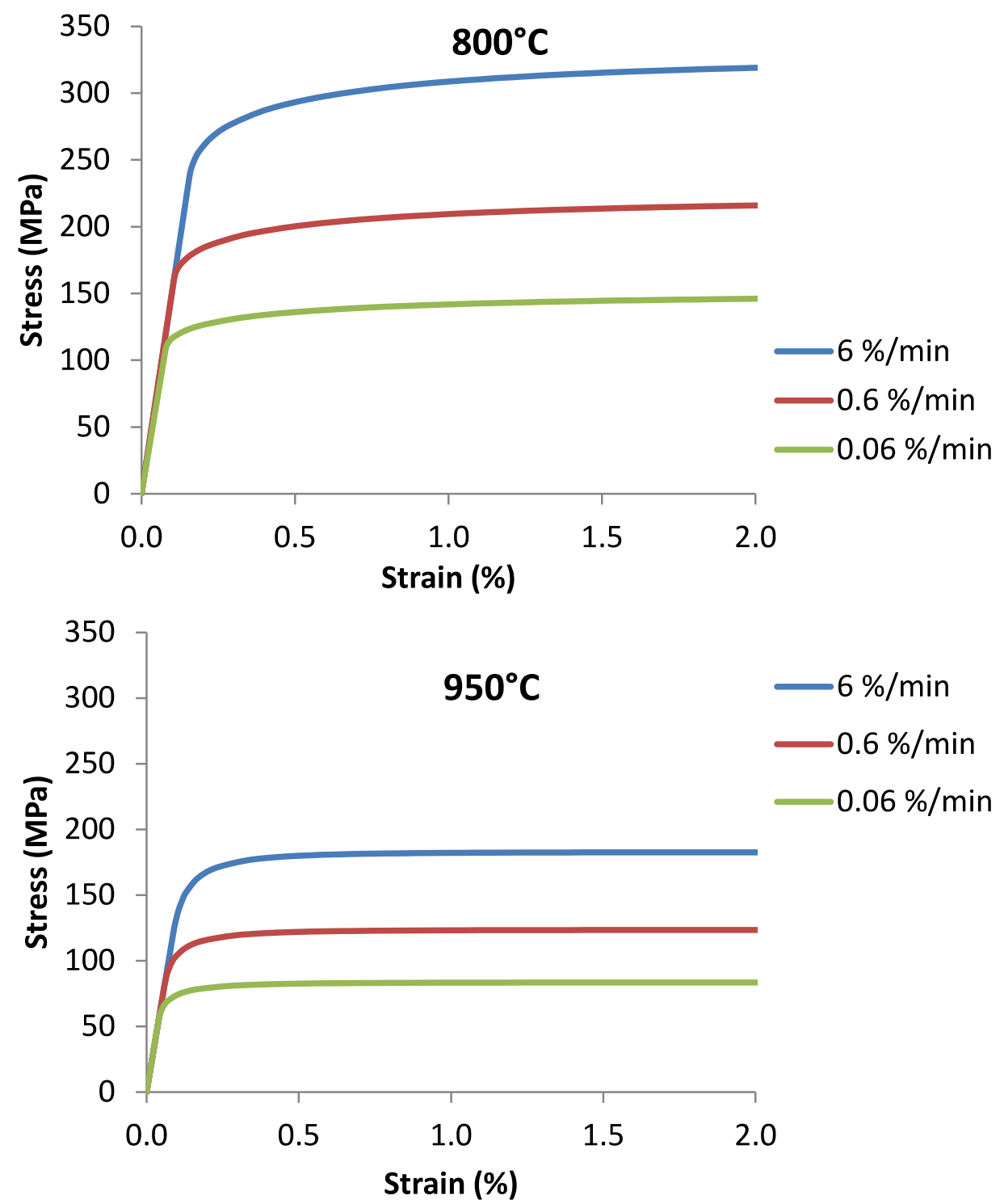

Figure 15. Hot tensile curves for various strain rates shown for two temperatures. 


\section{Isochronous Stress-Strain Curves \\ 5.1 Preliminary Approach using Zener-Hollomon}

The method outlined by Swindeman for $9 \mathrm{Cr}-1 \mathrm{Mo}-\mathrm{V}$ steel9 was also used as a starting point for developing ISSC for Alloy 617. A creep equation is used that combines primary and secondary contributions to calculate the creep strain at a given time:

$\mathrm{e}_{\mathrm{c}}=\mathrm{a}_{0} \mathrm{t}^{1 / 3}+\mathrm{mcr} \bullet \mathrm{t}$

where $t$ is time, $e_{c}$ is the creep strain, $a_{0}$ is a primary creep strain constant and mcr is the minimum creep rate. Both $\mathrm{a}_{0}$ and mcr are a function of stress and temperature. Since isochronous curves were limited to $2 \%$ strain, tertiary creep was not considered for the case of $9 \mathrm{Cr}-1 \mathrm{Mo}-\mathrm{V}$ steel.9

The minimum creep rate of Alloy 617 is well described by the Zener-Hollomon $(\mathrm{Z}-\mathrm{H})$ relation in the temperature range of $800-1000^{\circ} \mathrm{C}$ :

$\mathrm{Z}=\operatorname{mcr} \bullet \exp (-\mathrm{Q} / \mathrm{RT})$

where $\mathrm{Z}$ is the Zener-Hollomon parameter, $\mathrm{T}$ is temperature in $\mathrm{K}, \mathrm{R}$ is the universal gas constant, and Q is the activation energy. An activation energy of about $425 \mathrm{~kJ} / \mathrm{mol}$ is calculated from the creep data generated for the INL reference plate. When $\mathrm{Z}$ is plotted as a function of the Young's modulusnormalized stress, a power law fits the data:

$\mathrm{Z}=\mathrm{A}(\mathrm{S} / \mathrm{E})^{\mathrm{n}}$

where $\mathrm{n}$ is in the range of 5-6, and $\mathrm{E}$ is temperature-dependent Young's modulus. Rearranging equations 7 and 8 results in an equation for mor as a function of temperature and stress:

$\operatorname{mcr}=\mathrm{A}(\mathrm{S} / \mathrm{E})^{\mathrm{n}} \exp (\mathrm{Q} / \mathrm{RT})$

which is similar in form to that presented by Swindeman for $9 \mathrm{Cr}-1 \mathrm{Mo}-\mathrm{V}$ steel.9 A Z-H plot is shown in Figure $16 .{ }^{15,16}$ Note that the $750^{\circ} \mathrm{C}$ creep data also follows a $\mathrm{Z}-\mathrm{H}$ relation, although it is offset from the higher temperature data, indicating the presence of a threshold stress at $750^{\circ} \mathrm{C}$ that can be attributed to the presence of the $\gamma^{\prime}$ phase at this temperature. ${ }^{15}$

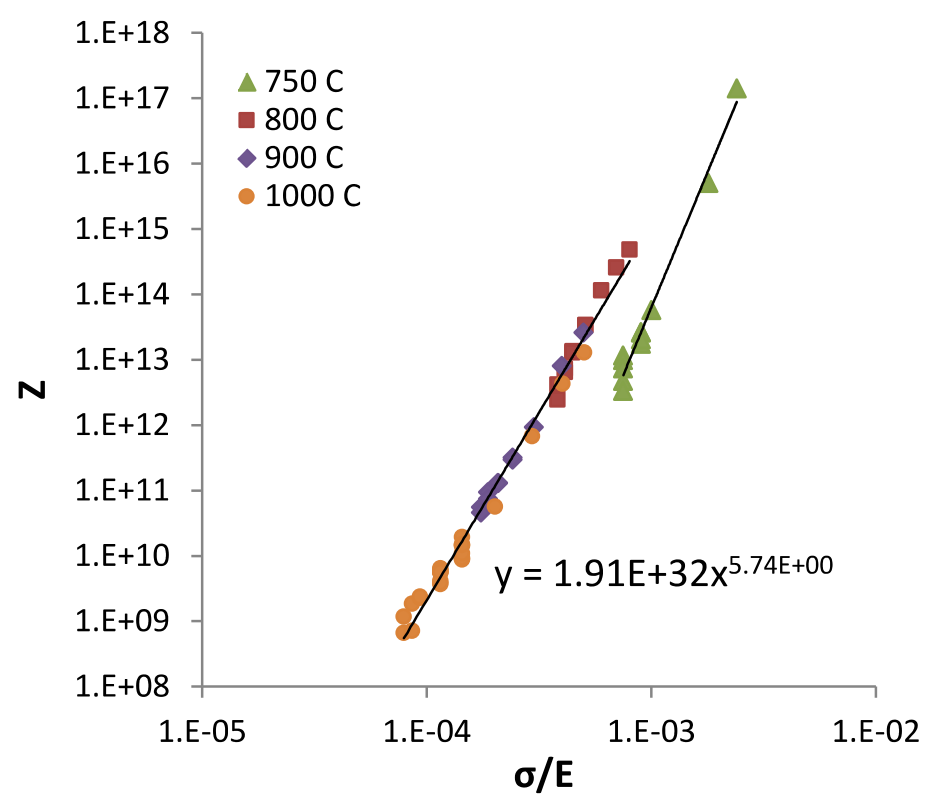

Figure 16. Zener Hollomon plot for Alloy 617. 
Swindeman gives an equation for $\mathrm{a}_{0}$ similar to the one he uses for mcr. Additional work is needed to verify if $\mathrm{a}_{0} \mathrm{t}^{1 / 3}$ is a valid description of the primary creep for Alloy 617 and if so to determine $\mathrm{a}_{0}$.

\subsection{Time to $1 \%$ Creep Strain}

The time-dependent stress intensity value is derived from creep experiments and has been stipulated as the minimum of :

- $2 / 3$ the creep rupture strength for time, $t$

- minimum stress to produce $1 \%$ creep strain

by both the draft Code Case and the German HTGR program. $8^{, 17}$ As Swindeman and Swindeman point out, the reciprocal of time to $1 \%$ strain is the average creep rate over the range of $0-2 \%$ strain, for which ISSCs are of interest.5 The L-M parameter is most often used to describe creep rupture behavior as a function of time, temperature and stress, as shown in Figure 5. However, the L-M parameter has also been used to plot time to $1 \%$ creep strain. 5 Figure 17 shows a Larson-Miller plot of the $1 \%$ creep strain data collected at INL in both creep-rupture and interrupted creep tests. The value of the constant, has not been optimized so the standard value of 20 has been used.

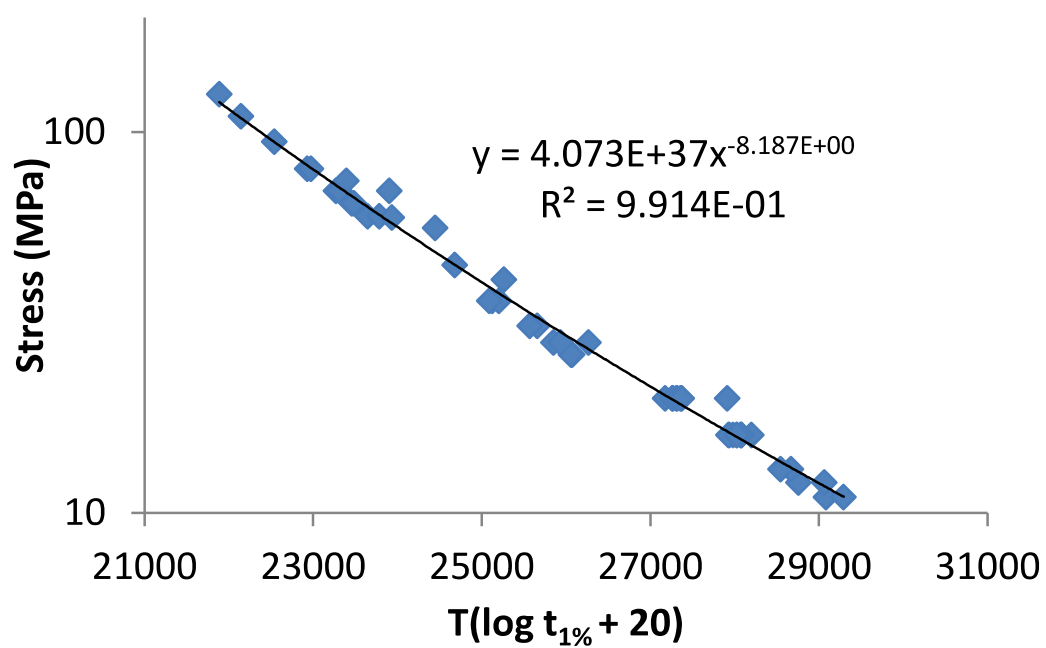

Figure 17. Time to $1 \%$ creep strain plotted with stress using the Larson-Miller parameter.

As a first approximation, the average creep strain $\left(1 / t_{1 \%}\right)$ is assumed to be constant over the range of $0-2 \%$ creep strain, resulting in linear creep curves. The experimental creep curves are fairly linear over this small strain range, however, using the L-M equation resulted in calculated average creep curves that did not match the experimental curves well, as can be seen for $800^{\circ} \mathrm{C}$ in Figure $18 \mathrm{a}$. If creep to $1 \%$ strain is plotted for each temperature (Figure 19) parallel power-law curves with an exponent of about -0.19 result. The calculated average creep curves taken from Figure 19 match experimental data better, as shown in Figure 18b. It appears that the L-M approach did not fit as well, simply because of the data scatter in Figure 17. However, the differences in the ISSC are not large, as shown in Figure 20. 

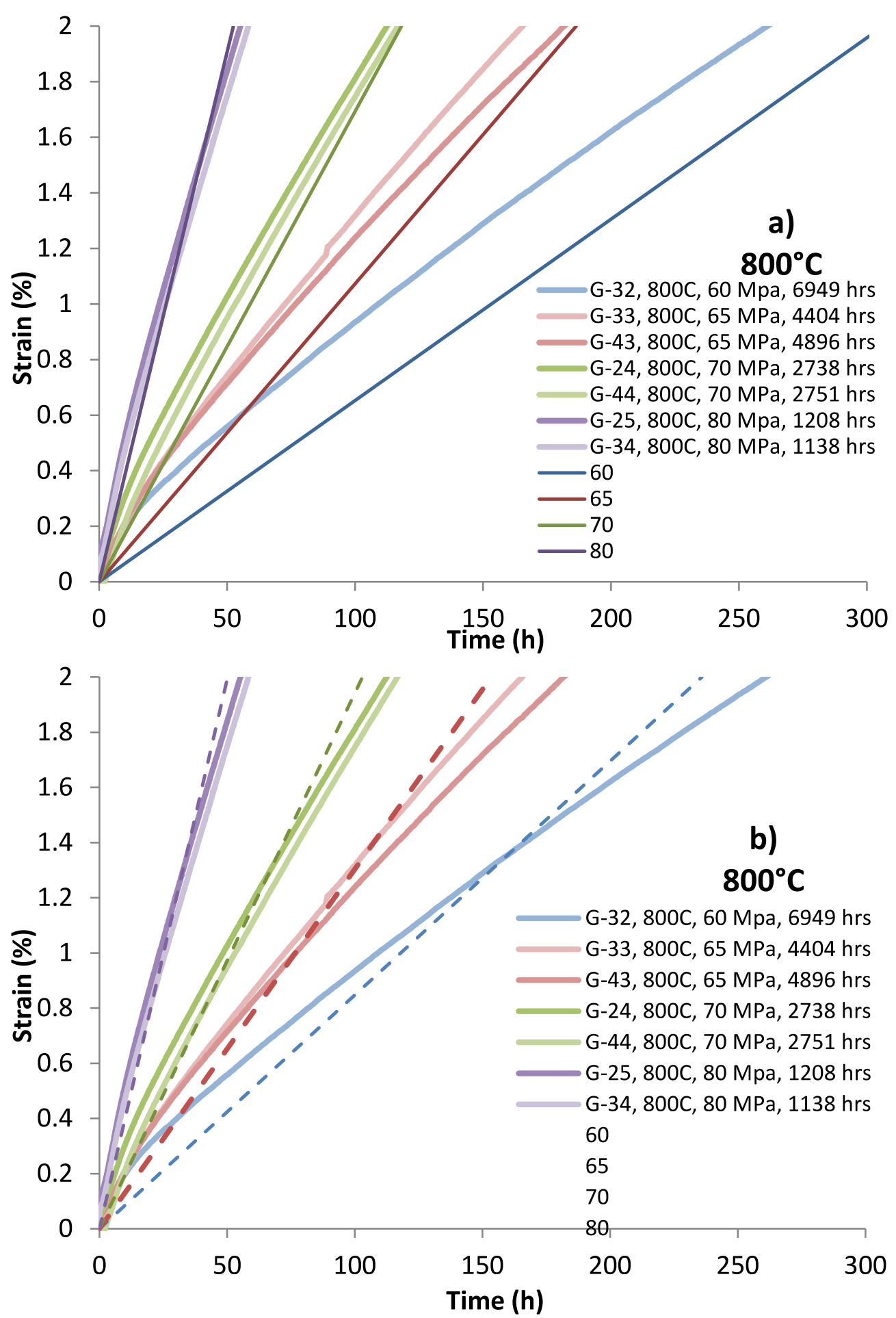

Figure 18. Comparison of $800^{\circ} \mathrm{C}$ experimental creep curves to calculated average creep curves up to $2 \%$ creep strain based on a) a Larson-Miller equation for a range of temperatures (Figure 17), and b) fits to temperature-specific curves (Figure 19). 


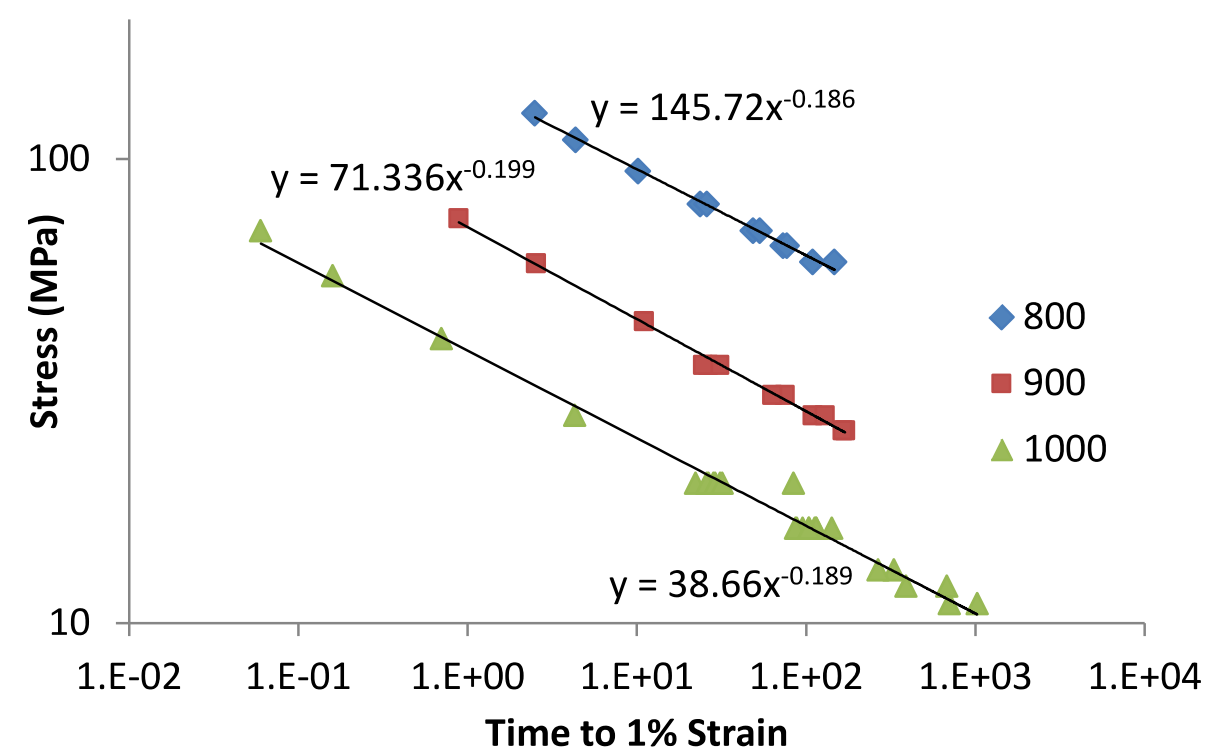

Figure 19. Stress vs. time to $1 \%$ strain.

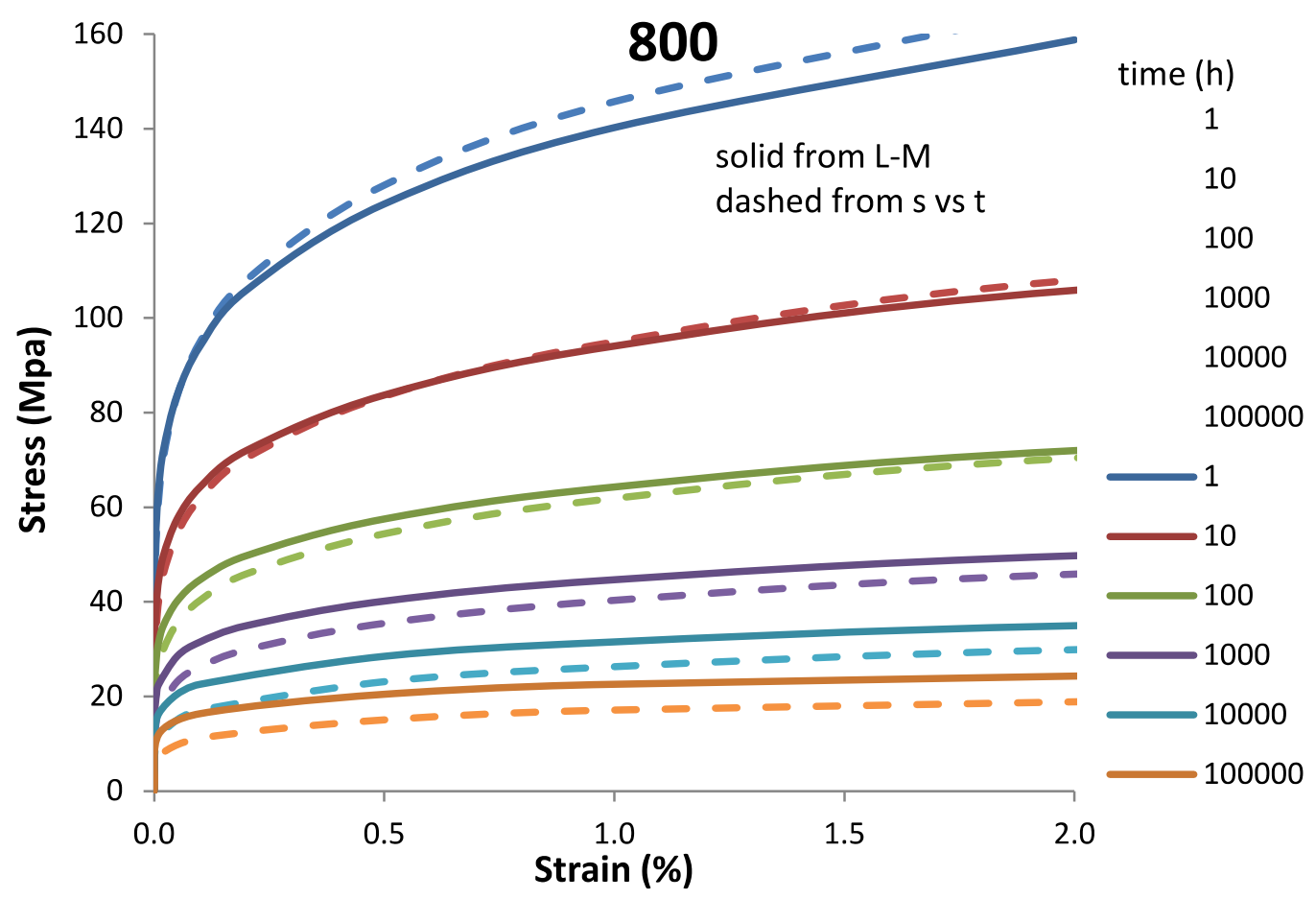

Figure 20. Isochronous stress-strain curves for $800^{\circ} \mathrm{C}$ claculated from L-M and strain to $1 \%$ creep.

ISSC calculated by the above method are compared to ISSC presented in the draft Code Case 8 and from the German HTGR program4 are presented in Figure 21 and Figure 22, respectively. Our preliminary ISSC are much lower than previously published ISSC. 

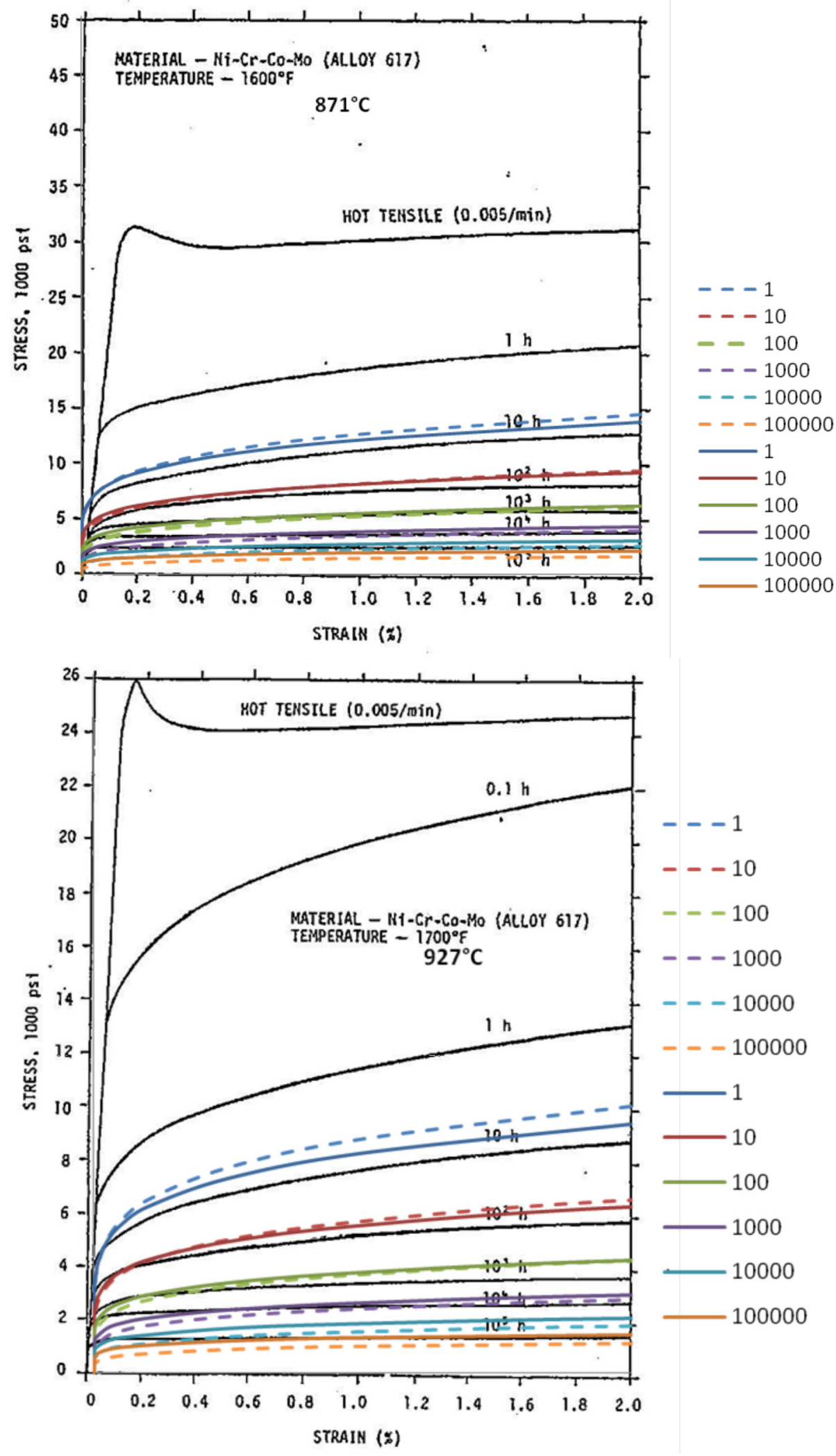

Figure 21. Comparison of calculated ISSC to ISSC presented in the draft Code Case. 

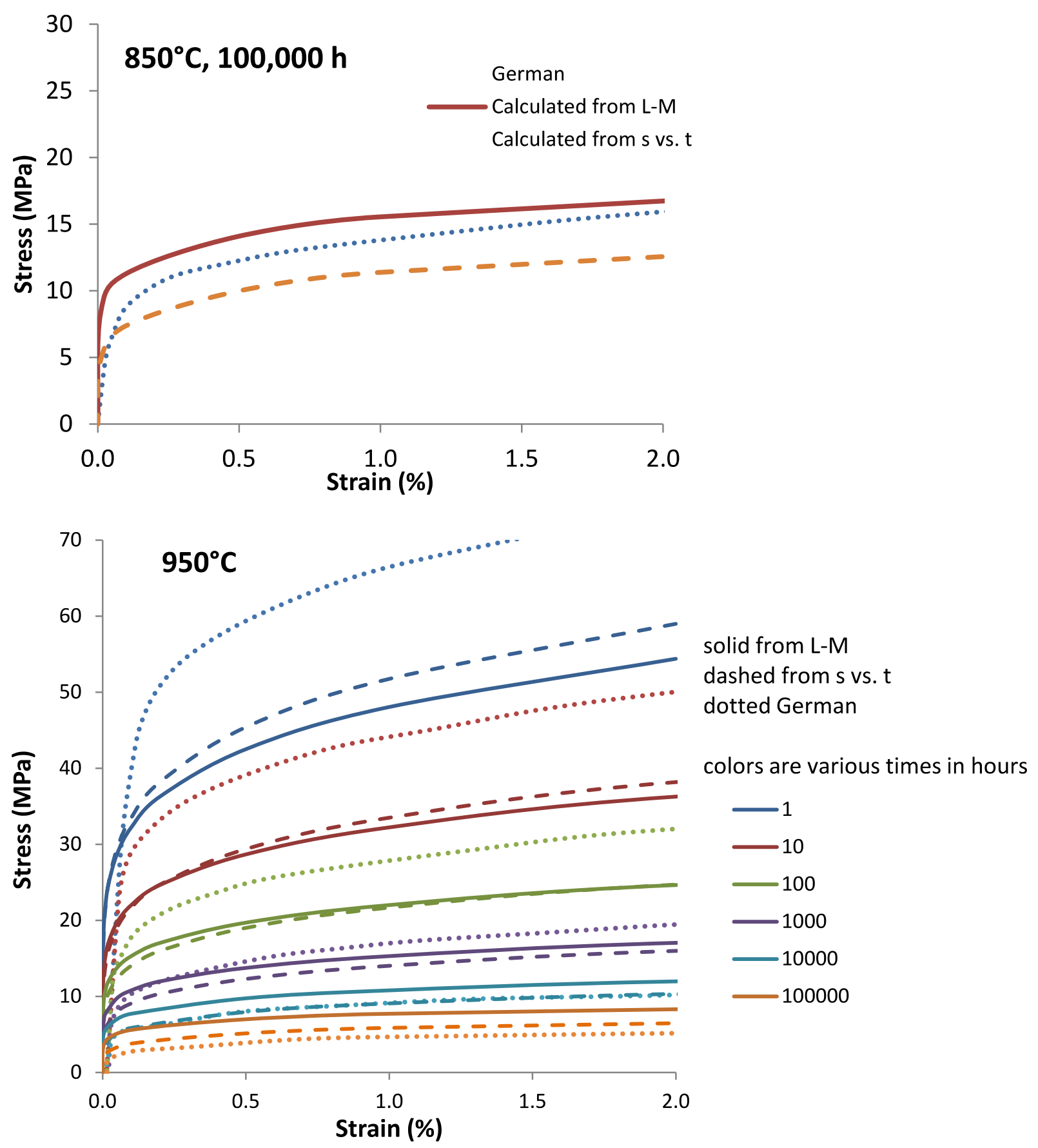

Figure 22. Comparison of calculated ISSC to those determined in the German program.

Data has been extracted and from experimental creep tests on the INL reference plate (performed at Argonne National Laboratory (ANL) and INL) at times of 1, 10, 100 and 1000 hours and plotted with the $760^{\circ} \mathrm{C}$ ISSC from the draft Code Case and the $950^{\circ} \mathrm{C}$ ISSC from the German HTGR program in Figure 23 and Figure 24, respectively. Longer creep times do not fall within 5\% creep strain for the stresses tested. Additional data from the KAERI (Korean Atomic Energy Research Institute) program have also been compared to the German ISSC, but the data have not been released for publication. Data from ANL fall in the range of the 100 and 1000h Code Case ISSCs, but below the 10h Code Case ISSC and the German ISSCs. INL data is above the Code Case ISSCs for all times. No $950^{\circ} \mathrm{C}$ creep tests were done at INL. 


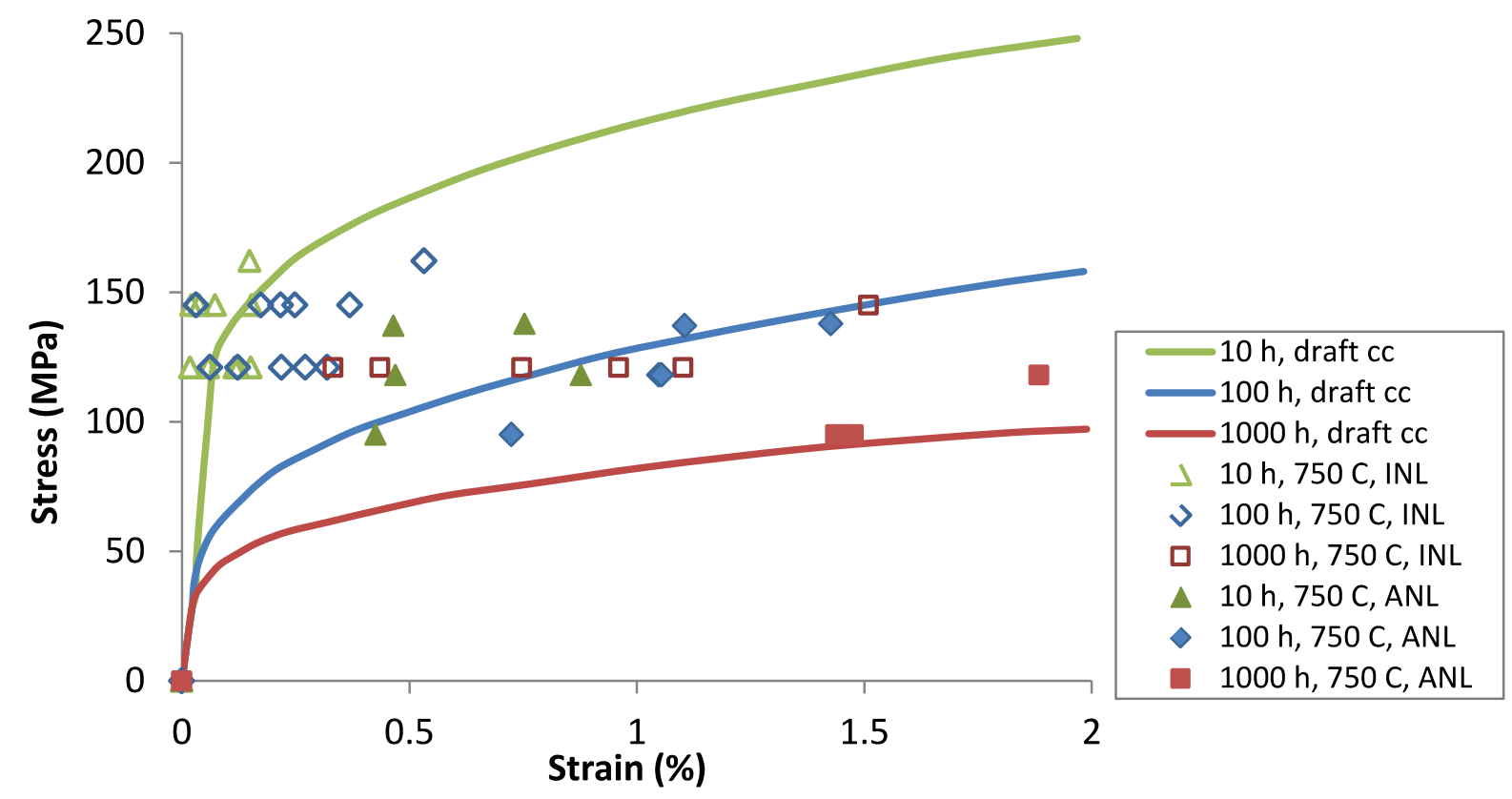

Figure 23. Draft Code Case isochronous stress-strain curves for $760^{\circ} \mathrm{C}$ with $750^{\circ} \mathrm{C}$ experimental data from INL and ANL (Argonne National Laboratory) on INL reference plate.

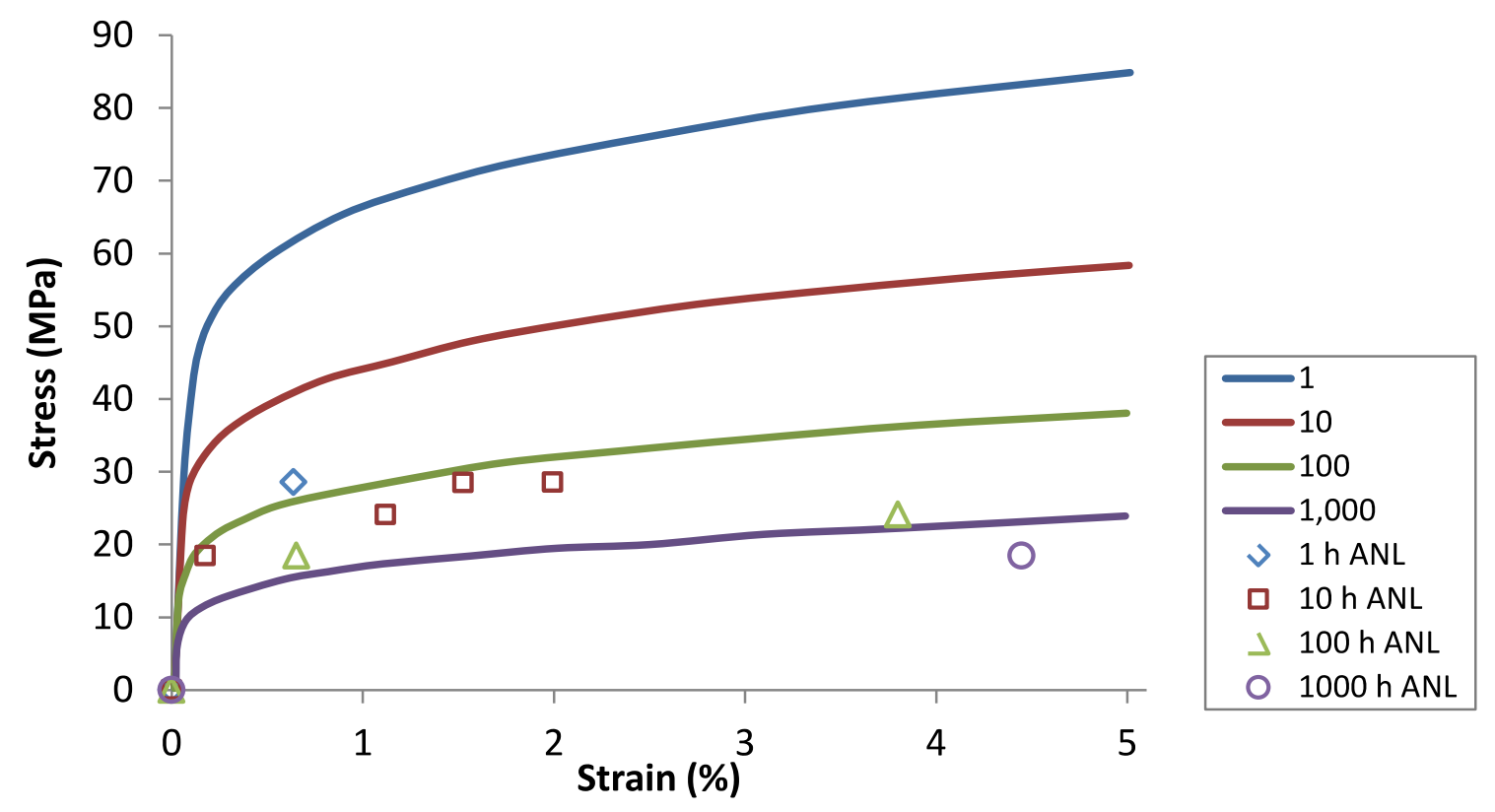

Figure 24. German isochronous stress-strain curves with experimental data from ANL on INL reference plate for $950^{\circ} \mathrm{C}$. 


\section{Conclusion}

Isochronous stress-strain curves are a significant requirement for qualification of a new material in Section III, Division 1, Subsection NH of the ASME Code for elevated temperature design. In this progress report, proposed curves from the German VHTR program and the US Draft Code Case have been recovered from historical records and are presented along with experimental data. There is some uncertainly about the details of the method used by the German program to determine the curves that have been published. There is a very limited amount of experimental data that can be used to evaluate how appropriate either approach is, particularly at long time. Work is continuing to evaluate the available experiments and analytical approaches to develop a set of curves that can be included in a draft Code Case.

It has been concluded that for many heats and product forms of mill annealed material that power-law creep is the dominant mechanism for temperatures and stresses relevant to VHTRs. Only in unusual cases where recrystallization to fine grain microstructures occurs is there potential for alternative creep mechanisms to become significant.

The high strain-rate sensitivity of Alloy 617 above $750^{\circ} \mathrm{C}$ introduces significant issues with the concept of a unique hot tensile curve. It is suggested that the hot tensile curve as a bounding condition for ISCCs above $750^{\circ} \mathrm{C}$ only has meaning if a strain rate is specified; a value of $0.5 \% / \mathrm{min}$ corresponding to the ASTM testing standard is suggested. 


\section{REFERENCES}

${ }^{1}$ Marriott, D. L., "Isochronous Stress/Strain Curves - Origins, Scope and Applications", Proceedings of the ASME 2011 Pressure Vessel and Piping Division Conference, (2011).

${ }^{2}$ Zhao, M. X. and Koves, W., "Isochronous Stress-Strain Method with General State of Stress and Variable Loading Conditions for Creep Evaluation", Journal of Pressure Vessel Technology, 134 (2012).

${ }^{3}$ Marriott, D. L., "Current Trends in High Temperature Design”, International Journal of Pressure Vessel and Piping, 50 (1992) 13-35.

${ }^{4}$ Duty, C. E. and T. E. McGreevy, T. E., "Impact of Deformation Mechanism Transition on Creep Behavior of Alloy 617”, ORNL/GEN4/LTR-06-017, July 30, 2006.

${ }^{5}$ Swindeman R. W. and Swindeman, M. J., "A Comparison of Creep Models for Nickel Base Alloys for Advanced Energy Systems," International Journal of Pressure Vessels and Piping, 85 (2008) 72-79.

${ }^{6}$ Swindeman, R., Swindeman, M. and Ren, W., "A Brief Review of Models Representing Creep of Alloy 617,” ASME, PVP2005-71784, July 2005.

${ }^{7}$ Corum, J. M. and Blass, J. J., "Rules for Design of Alloy 617 Nuclear Components to Very High Temperatures," PVP-Vol. 215 Fatigue, Fracture, and Risk, ASME, (1991) 147-153.

${ }^{8}$ Blass J. J., Corum J. M. and Chang S.-J., "Methods for Very High Temperature Design”, CONF890186-1, (1989).

${ }^{9}$ Swindeman, R. W. "Construction of isochronous Stress-Strain Curves for 9Cr-1Mo-V Steel”, PVP-Vol 391, Advances in Life Prediction Methodology, ASME, (1999) 95-100.

${ }^{10}$ Meurer, H. P., Gnirss, G. K. H., Mergler, W., Raule, G., Schuster, H. and Ullrich, G., "Investigations on the Fatigue Behavior of High-Temperature Alloys for High-Temperature Gas-Cooled Reactor Components," Nuclear Technology, 66(2), (1984) 315-323.

${ }^{11}$ Rao, K.B.S., Schiffers, H., Schuster, H. and Halford, G. R., "Temperature and Strain-Rate Effects on Low-Cycle Fatigue Behavior of Alloy 800H", Metallurgical and Materials Transactions A, 27A (1996) 255-267.

${ }^{12}$ Abd El-Azim, M. E., Mohamed, K. E. and Hammad, F. H., 1992, "The Deformation Characteristics of Alloy 800H and Alloy 617”, Mechanics of Materials, 14 (1992) 33-46.

${ }^{13}$ Wright, J. K., Carroll, L. J., Cabet, C., Lillo, T. M., Benz, J. K., Simpson, J. A., Lloyd, W. R., Chapman, J. A. and Wright, R. N., "Characterization of Elevated Temperature Properties of Heat Exchanger and Steam Generator Alloys," Nuclear Engineering and Design, 251 (2011) 252-261.

${ }^{14}$ Mulford, R. A. and Kocks, U. F., "New Observations on the Mechanisms of Dynamic Strain Aging and of Jerky Flow," Acta Metallurgica, 27 (1979) 1125-1134.

${ }^{15}$ Benz, J. K., Carroll, L. J., Wright, J. K., Wright, R. N. and Lillo, T. M., “Threshold Stress Creep Behavior of Alloy 617 at Intermediate Temperatures", Metallurgical and Materials Transactions A, (2014).

${ }^{16}$ Zener, C. and Hollomon, J., Journal of Applied Physics, 15 (1944) 22-32.

${ }^{17}$ Nickel, H. and Schubert, F. "Fundamental Principles for a Nuclear Design and Structural Analysis Code for HTR Components Operating at Temperatures above $800^{\circ} \mathrm{C}$," Nuclear Engineering and Design, 87 (1985) 345-355. 